\title{
Genome sequence of Xanthomonas fuscans subsp. fuscans strain 4834-R reveals that flagellar motility is not a general feature of xanthomonads
}

Armelle Darrasse ${ }^{1,2,3}$, Sébastien Carrère ${ }^{4,5}$, Valérie Barbe ${ }^{6}$, Tristan Boureau ${ }^{1,2,3}$, Mario L Arrieta-Ortiz ${ }^{7,14}$, Sophie Bonneau ${ }^{1,2,3}$, Martial Briand ${ }^{1,2,3}$, Chrystelle Brin ${ }^{1,2,3}$, Stéphane Cociancich ${ }^{8}$, Karine Durand ${ }^{1,2,3}$, Stéphanie Fouteau ${ }^{6}$, Lionel Gagnevin ${ }^{9,10}$, Fabien Guérin ${ }^{9,10}$, Endrick Guy ${ }^{4,5}$, Arnaud Indiana ${ }^{1,2,3}$, Ralf Koebnik ${ }^{11}$, Emmanuelle Lauber ${ }^{4,5}$, Alejandra Munoz ${ }^{7}$, Laurent D Noël ${ }^{4,5}$, Isabelle Pieretti ${ }^{8}$, Stéphane Poussier ${ }^{1,2,3,10}$, Olivier Pruvost ${ }^{9,10}$, Isabelle Robène-Soustrade ${ }^{9,10}$, Philippe Rott ${ }^{8}$, Monique Royer ${ }^{8}$, Laurana Serres-Giardi ${ }^{1,2,3}$, Boris Szurek ${ }^{11}$, Marie-Anne van Sluys ${ }^{12}$, Valérie Verdier ${ }^{11}$, Christian Vernière ${ }^{9,10}$, Matthieu Arlat ${ }^{4,5,13}$, Charles Manceau ${ }^{1,2,3,15}$ and Marie-Agnès Jacques ${ }^{1,2,3^{*}}$

\begin{abstract}
Background: Xanthomonads are plant-associated bacteria responsible for diseases on economically important crops. Xanthomonas fuscans subsp. fuscans (Xff) is one of the causal agents of common bacterial blight of bean. In this study, the complete genome sequence of strain Xff 4834-R was determined and compared to other Xanthomonas genome sequences.

Results: Comparative genomics analyses revealed core characteristics shared between Xff 4834-R and other xanthomonads including chemotaxis elements, two-component systems, TonB-dependent transporters, secretion systems (from T1SS to T6SS) and multiple effectors. For instance a repertoire of 29 Type 3 Effectors (T3Es) with two Transcription Activator-Like Effectors was predicted. Mobile elements were associated with major modifications in the genome structure and gene content in comparison to other Xanthomonas genomes. Notably, a deletion of $33 \mathrm{kbp}$ affects flagellum biosynthesis in Xff 4834-R. The presence of a complete flagellar cluster was assessed in a collection of more than 300 strains representing different species and pathovars of Xanthomonas. Five percent of the tested strains presented a deletion in the flagellar cluster and were non-motile. Moreover, half of the Xff strains isolated from the same epidemic than 4834-R was non-motile and this ratio was conserved in the strains colonizing the next bean seed generations.

Conclusions: This work describes the first genome of a Xanthomonas strain pathogenic on bean and reports the existence of non-motile xanthomonads belonging to different species and pathovars. Isolation of such Xff variants from a natural epidemic may suggest that flagellar motility is not a key function for in planta fitness.
\end{abstract}

Keywords: Seed-borne pathogen, Secretion system, Insertion sequence, Bean, Effector, Chemotaxis, Pseudogene

\footnotetext{
* Correspondence: Marie-Agnes.Jacques@angers.inra.fr

${ }^{1}$ INRA, UMR1345 Institut de Recherche en Horticulture et Semences, F-49071,

Beaucouzé, France

${ }^{2}$ AGROCAMPUS OUEST, UMR1345 Institut de Recherche en Horticulture et

Semences, F-49045, Angers, France

Full list of author information is available at the end of the article
} 


\section{Background}

Xanthomonads are plant-associated bacteria that establish neutral, commensal or pathogenic relationships with plants. Bacteria belonging to the genus Xanthomonas are known to be exclusively plant-associated organisms and do not colonize durably other niches. Globally, xanthomonads infect a wide range of economically important crops such as rice, banana, citrus, bean, tomato, pepper, sugarcane, and wheat. More than 124 monocotyledonous and 268 dicotyledonous plant species are hosts of xanthomonads $[1,2]$. The large host range of the genus strikingly contrasts with the typically narrow host range of individual strains that is restricted to one or several species of a botanical family [3]. Indeed, besides their very homogeneous phenotype, xanthomonads differ mainly by their host specificity. This is illustrated in the pathovar infrasubspecific division, which clusters bacterial strains causing similar symptoms on a same host range [4].

The common blight of bean (CBB), caused by $X$. axonopodis pv. phaseoli and X. fuscans subsp fuscans (Xff), is the most devastating bacterial disease of bean and one of the five major diseases of bean [5]. It causes significant yield loss that can exceed 40\% (http://www.eppo.int/QUARANTINE/bacteria/Xanthomonas_phaseoli/XANTPH_ds.pdf). Seed quality losses impact not only bean production but also seed industry worldwide. Its wide geographical distribution is presumed to be due to an efficient seed transmission. CBB affects seed and pod production and marketability of common bean (Phaseolus vulgaris L.) but also lima bean ( $P$. lunatus L.), tepary ( $P$. acutifolius A. Gray), scarlet runner bean (P. coccineus $\mathrm{L}$.$) , and several$ species belonging to Vigna [6]. Bean is a major crop all around the world; in the Americas and in Africa, bean is a staple crop and constitutes one of the main sources of protein for human (up to 60\%) and animal feeding [7]. Bean was domesticated independently in Mesoamerica and in the southern Andes more than 3,000 years ago $[8,9]$. Low to moderate levels of CBB resistance have been identified in a few common bean genotypes from the Mesomerican gene pool, whereas no resistance has been identified in the large-seeded Andean gene pool [10]. The tepary bean possesses the highest level of resistance, whereas only low levels of resistance have been found in common and scarlet runner beans [10]. These resistances have been introgressed into common bean breeding lines but with little success into common bean cultivars of any market class [11]. To date, at least 24 different CBB resistance QTLs have been reported across all eleven linkage groups of common bean [11].

$X$. axonopodis pv. phaseoli and Xff colonizes both vascular tissues and parenchyma of their host. CBB agents survive epiphytically until favorable conditions for infection are reached [12]. These bacteria are well adapted to survive harsh phyllosphere conditions following epiphytic aggregation in biofilms [13]. Penetration through stomata is thought to lead to bacterial colonization of the mesophyll, causing leaf spots. Bacteria progression inside the host leads to the colonization of vascular tissues, but the wilting of the plant is observed only in severe cases of infection [6]. Main CBB symptoms are spots and necrosis, which appear on leaves, stems, pods and seeds. They are especially severe in tropical wet regions [6]. Bacterial ooze may be encountered especially on stems and pods, providing inoculum for secondary spread. In seeds, spots can be distributed all over the seed coat or restricted to the hilum area. Most notably, contamination occurs on plants and seeds that are symptomless, raising concerns about pathogen transmission $[13,14]$.

Many important pathogenicity factors have been described for xanthomonads. To establish themselves successfully in host plants, xanthomonads first adhere to the plant surface, invade the intercellular space of the host tissue, acquire nutrients and counteract plant defense responses. The secretion of effectors into the extracellular milieu or directly into the host cell cytosol leads to successful host infection. The virulence factors allowing xanthomonads to complete these steps include adhesins, EPS, LPS, degradative enzymes and type three effectors (T3Es) [15]. CBB agents are known to secrete several fimbrial and non-fimbrial adhesins, some of which are involved in aggressiveness [16]. The mucoid appearance of Xap and Xff bacterial colonies is an indication of xanthan production, which is under the regulation of the diffusible factor DSF (our unpublished data). The role of the hrpType Three secretion System (T3SS) in infection and bacterial transmission to seed has been previously demonstrated [17]. A specific repertoire of 12 to 19 T3Es per strain of Xap and Xff strains has been determined [18]. However, a comprehensive characterization of all virulence factors in $\mathrm{CBB}$ agents remains to be proposed, and the genome deciphering of Xff and Xap strains is a first step in this direction.

CBB was first described in 1897 and the taxonomy of infecting strains is still debated since they are genetically diverse but share a common host (Phaseolus vulgaris) on which they induce the same range of symptoms. Among these strains, some produce a brown pigment on tyrosine-containing medium, therefore are called fuscous strains. The pigment results from the secretion and oxidation of homogentisic acid (2,5 dihydroxyphenyl acetic acid), an intermediate in the tyrosine catabolic pathway [19]. These strains are referred to as variant fuscans and are usually highly aggressive on bean $[20,21]$ although the pigment itself has not been directly associated with pathogenicity $[22,23]$. Up to 1995 , fuscous and nonfuscous strains responsible for CBB were grouped in a single taxon, namely, $X$. campestris pv. phaseoli. Genetic diversity of strains responsible for $\mathrm{CBB}$ was 
demonstrated by rep-PCR [24], AFLP [25] and recently by MLSA [26]. Three genetic lineages (GL2, GL3 and GLfuscans) are phylogenetically closely related and belong to rep-PCR group 6 [27] while GL1 is phylogenetically distant and belongs to rep-PCR group $4[25,26]$. Following taxonomical revision of the Xanthomonas genus, this pathovar was transferred to $X$. axonopodis, fuscous strains forming a variant within this pathovar $[2,3]$. The current taxonomically valid nomenclature for the strains responsible for CBB is Xanthomonas fuscans subsp. fuscans (Xff) for the fuscous strains, and Xanthomonas axonopodis pv. phaseoli for the non-fuscous strains [28]. Fuscous strains were first isolated by Burkholder from beans grown in Switzerland in 1924 [29] and have been isolated from every bean production area throughout the world since this date. The strain 4834-R is a highly aggressive strain that was isolated from a seed-borne epidemic in France in 1998 [13].

Twelve complete genome sequences of Xanthomonas are currently available and more than 90 draft Xanthomonas genomes (www.xanthomonas.org/genomes.html) are deposited in public databases. Altogether, genomes are available for strains representing 13 pathovars spanning over 11 Xanthomonas species. Most of the sequenced strains are pathogenic to five plant taxa (cabbage, cassava, citrus, rice, and sugarcane). No complete fully assembled genome sequence is yet available for any xanthomonads pathogenic to legumes. However the draft sequence of $X$. axonopodis pv. glycines strain 12-2, a pathogen of soybean, was recently made available (accession number: AJJO00000000). Common characteristics of previously released Xanthomonas genomes are to hold a great number of genes encoding proteins devoted to plant environment recognition such as methyl-accepting chemotaxis protein (MCP) and other sensors, to plant substrates exploitation such as TonB-dependent transporters (TBDT) and cell wall-degrading enzymes (CWDE), and to manipulation of plant defense machinery such as T3Es [30]. These bacteria contain genes encoding the six types of protein secretion systems so far described in Gram-negative bacteria. All these $\gamma$-proteobacteria are motile by a single polar flagellum. Motility is an important feature involved in plant colonization and is often considered as a pathogenicity factor. One motif of the bacterial flagellum (flg22) is a microbial-associated molecular pattern (MAMP) recognized by a transmembrane pattern-recognition receptor (FLS2) leading to PAMP-triggered immunity (PTI) [31]. Bean is known to harbor a FLS2-like gene, which expression is regulated following fungal infection [32].

Here, we provide the first whole-genome sequence of a Xanthomonas pathogenic on legumes. The high quality fully assembled and manually annotated genome sequence of $X$. fuscans subsp. fuscans strain 4834-R (Xff 4834- $\mathrm{R}$ ) reveals a strong potential for adaptation to versatile environments, which appears to be a hallmark for xanthomonads.

\section{Results and discussion}

Xff 4834-R presents the classical general features of xanthomonads genomes

A high quality fully assembled sequence of the genome of Xff 4834-R was obtained by combining 454GS-FLX Titanium pyrosequencing (20X coverage), Illumina $36 \mathrm{bp}$ (76X coverage) and Sanger (4X coverage) sequencing. The genome of Xff 4834- $\mathrm{R}$ is composed of a circular chromosome and three extrachromosomal plasmids ( $\mathrm{a}, \mathrm{b}$ and $\mathrm{c}$ ) with a total size of 5088,683 bp (Figure 1). The average GC content of Xff 4834-R chromosome is $64.81 \%$, while average GC content of plasmids a, b and c are $61.32 \%$, $60.64 \%$ and $60 \%$, respectively. This high GC content is a common characteristic of most genera within the Xanthomonadaceae family [33]. The circular chromosome GC skew pattern is typical of prokaryotic genomes with two major shifts located near the origin and terminus of replication. The dnaA gene, which encodes a replication initiation factor promoting the unwinding of DNA at oriC, defines by convention the origin of the chromosomal sequence of Xff 4834-R. Annotation of the Xff 4834-R genome sequence revealed a total of 4,083 putative proteincoding sequences (CDSs), 137 pseudogenes, 127 insertion sequences (ISs), 54 tRNA and six rRNA genes. The rRNA genes (5S, 23S and 16S) are typically organized in two identical operons localized 463,865 bp apart. This genetic organization is a common characteristic of the other Xanthomonas strains sequenced (http://xanthomonas.org/ genomes.html), with the exception of $X$. albilineans, which presents a reduced genome [34].

Of the 4,083 manually annotated CDSs, 3,021 have been assigned to putative functions based on homology with other known proteins and functional domain analyses (Table 1). Overall, automatic identification of clusters of orthologous groups of proteins (COGs) did not reveal any major difference in functions predicted in Xff 4834- $\mathrm{R}$ genome compared to the genomes of other Xanthomonas sp. (data not shown).

\section{Xanthomonads pan-genome and comparative genomics}

The pan-genome of a bacterial genus, species or group of strains is composed of a core genome (genes shared by all individuals) and a dispensable genome consisting of partially shared and strain-specific genes [36]. The dispensable fraction reflects the diversity of the group and may contain genes involved in the diversity of lifestyles [37], Xanthomonas pathogenicity, and adaptation to host and tissues $[30,38,39]$. Based on the phylogeny of the Xanthomonas genus [40] and the quality of the genomic sequences, we chose 12 other genomes to perform comparative genomics analyses with Xff 4834-R (Table 2). 


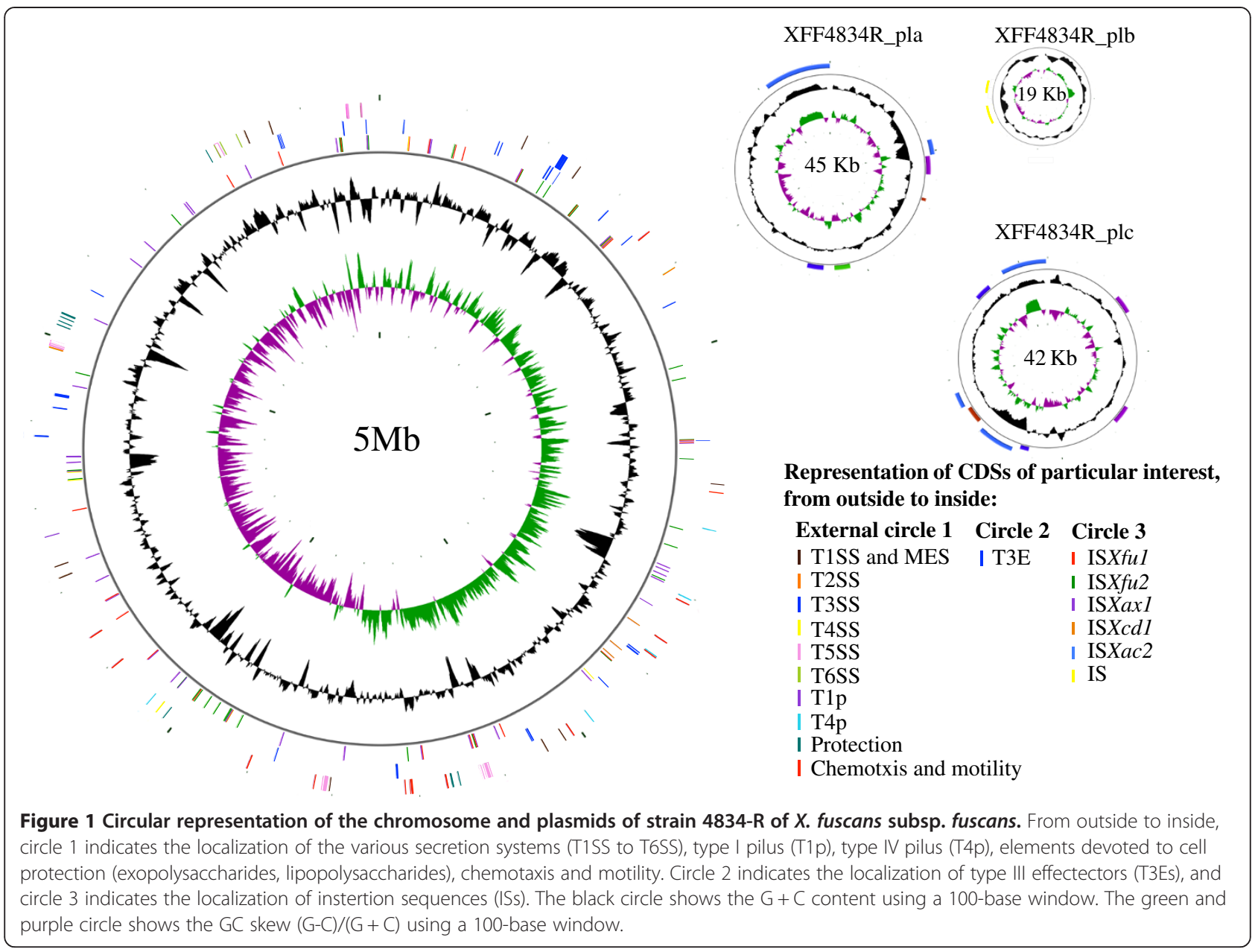

These strains were chosen to represent different lifestyles and different host / tissue specificities.

\section{More than $80 \%$ of CDSs unique to Xff $4834-R$ encodes hypothetical proteins.}

The 13 genomes of Xanthomonas have various sizes (containing between 3,028 and 5,027 CDSs) and totalize 56,614 CDSs. This Xanthomonas pan-genome includes orthologs, paralogs, and CDSs that are specific of each strain (Figure 2). The core genome of the 13 Xanthomonas genomes contains 1,396 groups of orthologs $(18,148$ CDSs), which are defined as copy-unique genes present in every genome and also 195 groups of homologs (3,117 CDSs), which are conserved in all strains but have at least one in-paralog in at least one strain. The Xanthomonas core genome represents in average 30\% of any Xanthomonas genome. This value is high compared to the core genome size of the highly diverse Lactobacillus, which represents approximately $15 \%$ of any Lactobacillus genome [49]. The Xanthomonas core genome increases to $44 \%$ of any Xanthomonas genome once $X$. albilineans strain GPE PC73 (Xal GPE PC73) is excluded of the analysis. This result is probably due to the markedly reduced genome of Xal GPE PC73 [34] and to its phylogenetic distance with all other Xanthomonas strains used in this study (Additional file 1).

The remaining CDSs $(35,349)$ constitute the dispensable genome (3,270 groups of orthologs, 5,533 CDSs with paralogs, and 7,835 specific CDSs). The conserved fraction of the dispensable genome, i.e. CDSs present in 10 to 12 genomes, contains 1,591 groups of homologs (16,454 CDSs). The variable fraction, i.e. CDSs present in five to nine genomes, totalizes 782 groups of homologs $(6,379$ CDSs), whereas rare homologs, i.e. distributed in two to four genomes are in 1,581 groups $(4,682$ CDSs). Among those, pairwise comparisons of CDS contents in the sequenced genomes show a limited number of genes that are shared exclusively between two strains. As expected, the phylogenetically-closest strains share the highest number of CDSs (Additional file 1). In contrast, Xff 4834-R shares several CDSs with Xal GPE PC73. These genes have been probably acquired by horizontal gene transfert (HGT) events (Additional file 1). Indeed, most of these CDS (10/14) are located on 
Table 1 Putative functions assigned to Xff 4834-R CDSs according to Riley classification [35]

\begin{tabular}{|c|c|c|}
\hline Main functional class ${ }^{1}$ & $\begin{array}{l}\text { Gene ontology } \\
\text { number (GO) }\end{array}$ & $\begin{array}{l}\text { Number } \\
\text { of CDSs }\end{array}$ \\
\hline 1. Metabolism & GO:0008152 & 1,248 \\
\hline 1.1. Carbon compounds utilization & & 142 \\
\hline 1.2. Macromolecules degradation & GO:0009057 & 151 \\
\hline 1.3 Energy metabolism (carbon) & GO:0015980 & 83 \\
\hline 1.4 Energy production/transport & & 57 \\
\hline 1.5. Building block biosynthesis & & 260 \\
\hline 1.6. Macromolecules biosynthesis & GO:0009059 & 214 \\
\hline 1.7. Central intermediary metabolism & & 82 \\
\hline 1.8. Metabolism of other compounds & & 20 \\
\hline 2. Information transfer & & 371 \\
\hline 3. Regulation & GO:0050789 & 360 \\
\hline 4. Transport & GO:0005215, GO:0006810 & 489 \\
\hline 5. Cell processes & GO:0009987 & 186 \\
\hline 6. Cell structure & GO:0005575 & 34 \\
\hline 7. Location of gene products & GO:0005575 & 199 \\
\hline 8. Extrachromosomal & & 136 \\
\hline \multicolumn{3}{|l|}{ 9. DNA sites } \\
\hline 10. Cryptic genes & & 1,060 \\
\hline
\end{tabular}

${ }^{1}$ Only one putative functional class was assigned per CDS.

plasmids; the others being clustered on the chromosome (cf. LPS section). At least 6,979 unique CDSs and 856 specific CDSs with paralogs constitute the strain-specific fraction of Xanthomonas pan-genome. The number of strain-specific genes is variable within the 13 Xanthomonas genomes; Xff 4834-R displays one of the smallest fractions of specific genes (Figure 2). The specific Xff 4834-R CDSs mainly encode hypothetical proteins
(83.3\% of the specific CDSs vs. $26 \%$ of the whole Xff 4834- $\mathrm{R}$ predicted proteome), a feature already observed in other comparative genomics analyses [36,50,51]. Regarding the origin of the Xff4834-R specific CDSs, $17.5 \%$ have a plasmidic origin and $15.9 \%$ are located in the vicinity of ISs. However, only $1.6 \%$ of Xff4834-R specific CDSs are associated with phage insertion. In addition, some Xff 4834-R specific CDSs also encode the T3E XopT, several regulators, transporters and secreted proteins (Additional file 2). However, increasing the number of Xanthomonas genomes in the comparison should decrease the number of Xff 4834-R specific CDSs observed in this study. For instance, the gene $x o p T$ is present in the strains X. oryzae pv. oryzae strain KACC10331 and MAFF311018, which have not been used in our analysis. Moreover, the CDSs of the specific fraction of Xff 4834$\mathrm{R}$ may be not conserved in other Xff-related strains. Therefore, the prevalence of Xff 4834-R specific genes among large collections of strains deserves further analysis. Genomic comparisons provide candidates for further functional studies of Xff host colonization

The genome of Xff 4834-R was compared to different bacterial genomic sequences in order to identify functions or putative CDSs involved in plant pathogenicity and adaptation to different ecological niches (Figure 3). To get insights into functions involved in plant pathogenicity, xylem and parenchyma adaptation, the genome of Xff 4834-R was compared to the genomic sequences of a non-pathogenic plant endophytic isolate, $S m$ R5513 , and a xylem-limited plant pathogen, $X f$ Temecula 1. Both strains belong to the Xanthomonadaceae family. $X f$ Temecula 1 presents a reduced genome and is insectvectored [48,52]. Orthologs shared by Xff 4834-R and Xf Temecula 1 differ significantly in Riley functional classes [35] in comparison to the whole predicted proteomes

Table 2 List of genome sequences used in comparative genomics

\begin{tabular}{|c|c|c|c|c|c|}
\hline Accession & Nomenclature & Strain code & Tissue specificity & Host & Reference \\
\hline PRJNA58657 & Stenotrophomonas maltophilia (Sm) & R551-3 & Non-pathogenic endophyte & Poplar & Unpublished \\
\hline PRJNA43163 & Xanthomonas albilineans (Xal) & GPE PC73 & Vascular pathogen & Sugarcane & {$[34]$} \\
\hline PRJNA73179 & X. axonopodis subsp. citrumelonis (Xacm) & F1 & Non-vascular pathogen & Citrus & {$[41]$} \\
\hline PRJNA57887 & X. campestris pv. campestris (Xcc) & ATCC33913 & Vascular pathogen & Brassicacaeae & {$[42]$} \\
\hline PRJNA55437 & X. campestris pv. musacearum $(X \mathrm{~cm})$ & NCPPB4381 & Vascular pathogen & Banana & {$[43]$} \\
\hline PRJNA159539 & X. campestris pv. raphani $(X c r)$ & $756 C$ & Non-vascular pathogen & Brassica spp. & {$[39]$} \\
\hline PRJNA57889 & $X$. citri subsp. citri (Xac) & 306 & Non-vascular pathogen & Citrus & {$[42]$} \\
\hline PRJNA58321 & $X$. euvesicatoria $(X C V)$ & $85-10$ & Non-vascular pathogen & Tomato and sweet pepper & {$[44]$} \\
\hline PRJNA47495 & $X$. fuscans subsp. aurantifolii (Xfa) & ICPB10535 & Non-vascular pathogen & Citrus & {$[45]$} \\
\hline PRJNA63615 & X. gardneri $(X g)$ & ATCC19865 & Non-vascular pathogen & Tomato and sweet pepper & {$[46]$} \\
\hline PRJNA153105 & X. oryzae pv. oryzae (Xoo) & PXO99A & Vascular pathogen & Rice & [47] \\
\hline PRJNA54411 & X. oryzae pv. oryzicola (Xoc) & BLS256 & Non-vascular pathogen & Rice & {$[39]$} \\
\hline PRJNA63613 & $X$. vesicatoria $\left(X_{V}\right)$ & ATCC35937 & Non-vascular pathogen & Tomato and sweet pepper & {$[46]$} \\
\hline PRJNA57869 & Xylella fastidiosa $(X f)$ & Temecula1 & Vascular pathogen, insect-transmitted & Grapewine & {$[48]$} \\
\hline
\end{tabular}




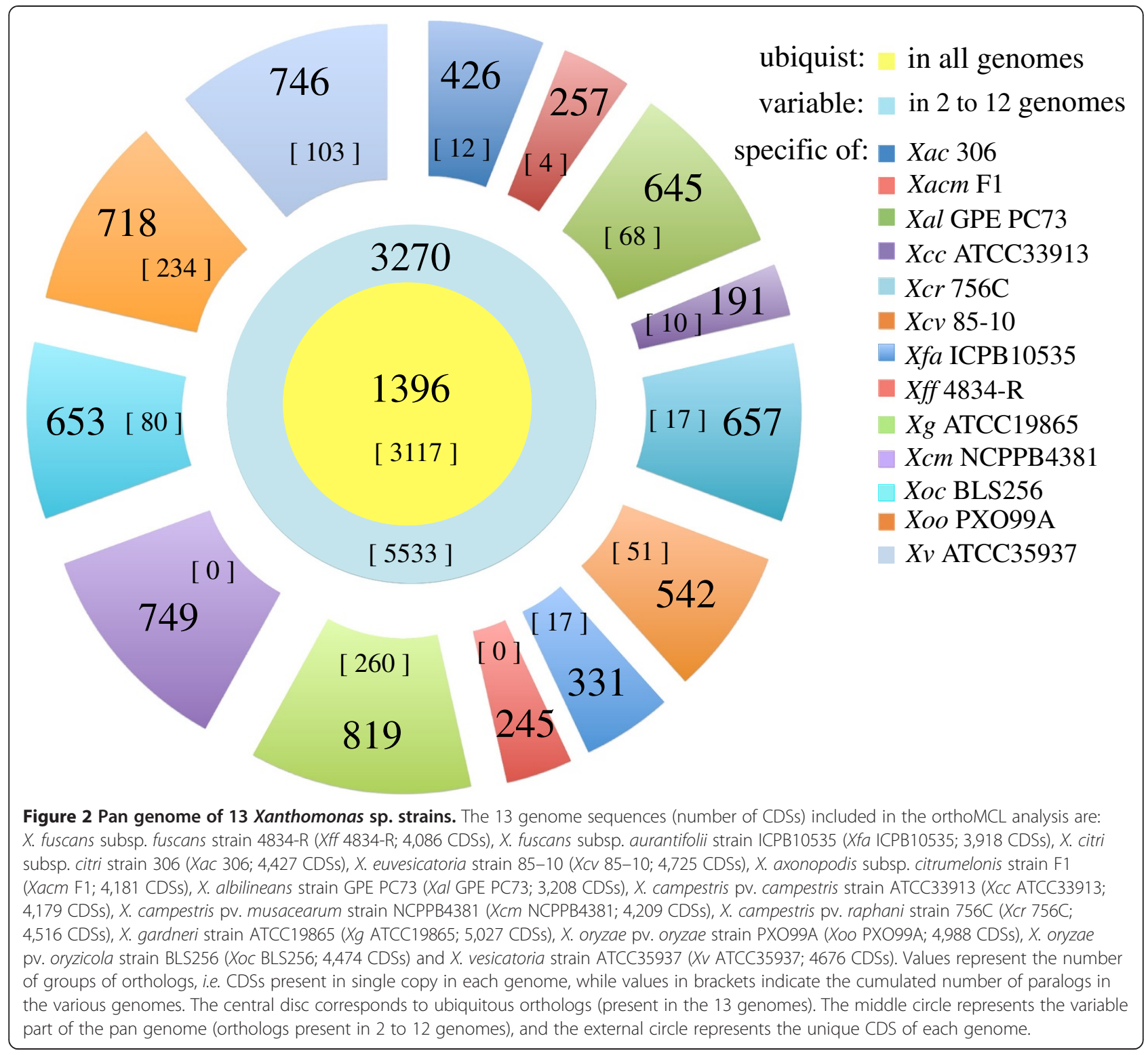

(calculated $X^{2}=118.69 ; X^{2}{ }_{01}\left[8_{]}=20.09\right.$ ). For instance, CDSs involved in metabolism are enriched in the orthologous fraction shared between Xff 4834- $\mathrm{R}$ and $X f \mathrm{Te}$ mecula in comparison with the whole genomes $(42.2 \%$ vs. $30.5 \%$, respectively). Among them, there are CDSs involved in xanthan biosynthesis and several depolymerizing carbohydrates enzymes that could be involved in plant pathogenicity and xylem colonization. Orthologs shared by Xff 4834-R and Sm R551-3 also differ significantly in Riley functional classes in comparison to the whole predicted proteomes (calculated $X^{2}=100.53 ; X^{2}$ ${ }_{01}\left[8_{3}=20.09\right)$. CDSs involved in regulation, transport, chemotaxis and motility are enriched in the orthologous groups shared by Xff 4834-R and Sm R551-3. These functional categories are generally abundant in metabolically versatile prokaryotes capable of survival in complex and variable environmental niches, especially in nutrient-scarce environments [53]. This observation is in agreement with the ability of Xff to survive in the phyllopshere $[13,16,17]$, an environment which is known to be nutrient-limited [54].

In order to identify functions putatively involved in tissue colonization, the genome sequence of Xff 4834-R was compared to the genome sequences of two rice pathogens Xoo PXO99A and Xoc BLS256. While Xff colonizes both the vascular system and the parenchyma of its host, Xoo PXO99A and Xoc BLS256 colonize specifically the vascular system and the parenchyma of their host, respectively. Orthologs shared by Xff 4834-R and Xoc BLS256 differ significantly in Riley functional classes in comparison to the whole predicted proteomes (calculated $\left.\mathbf{X}^{2}=180.08 ; \mathbf{X}^{2}{ }_{01[} 8_{]}=20.09\right)$. For example, CDSs 


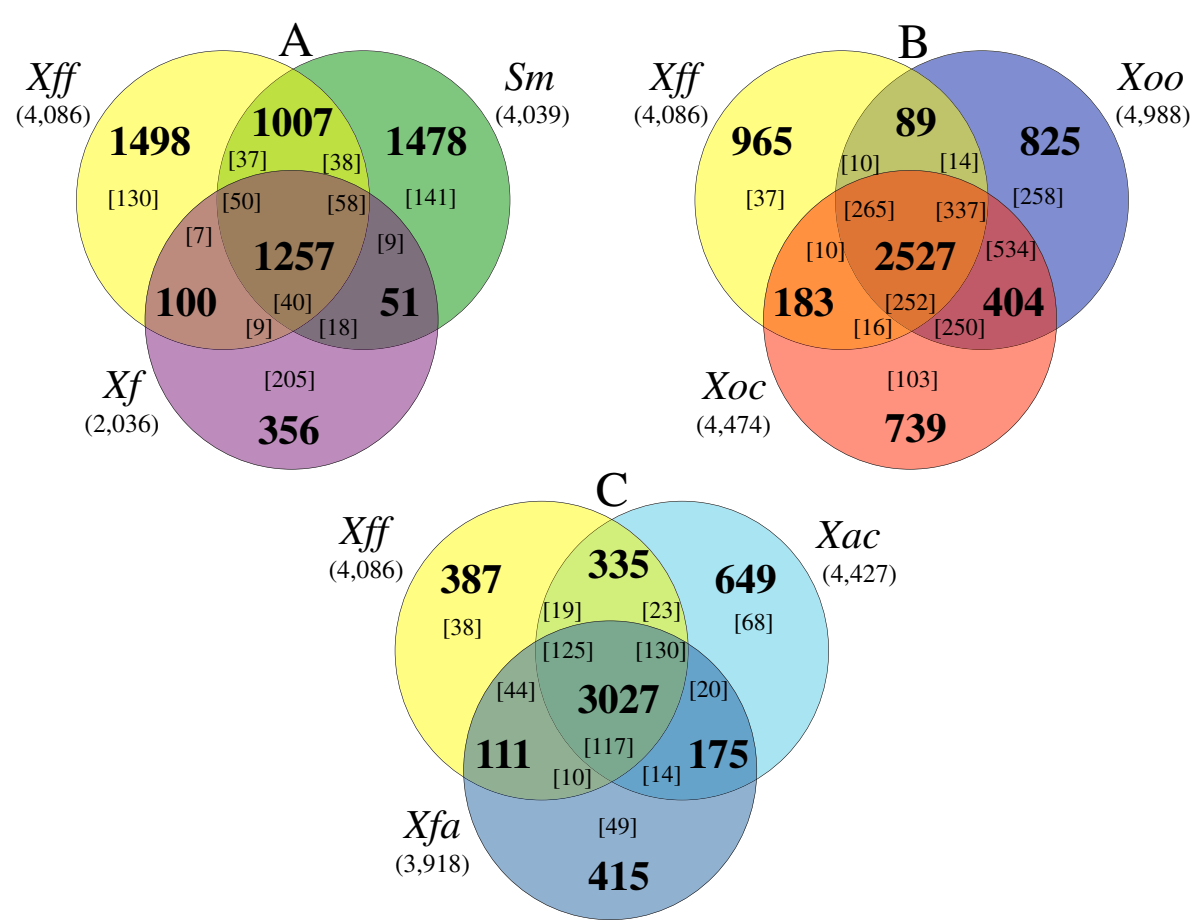

Figure 3 Venn diagrams illustrating the comparisons of xanthomonads genomes. Venn diagrams display the number of CDSs, which are present in single copy in each genome (in bold). In addition, values in brackets indicate the cumulated number of paralogs. (A) Comparison of the genomes of Xanthomonas fuscans subsp. fuscans strain 4834-R (Xff) and two distantly related strains: Stenotrophomonas maltophilia strain R551-3 $(\mathrm{Sm})$, a non-pathogenic endophyte of poplar, and Xyllella fastidiosa strain Temecula 1 (Xf), an insect-vectored pathogen of grapevine. (B) Comparison of genomes of Xff 4834-R and two strains belonging to X. oryzae: X. oryzae pv. oryzae strain PXO99A (Xoo), a vacular pathogen of rice, and X. oryzae pv. orizycola strain BLS256 (Xoc), a non-vascular pathogen of rice. (C) Comparison of genomes of Xff 4834-R with two phylogenetically close strains: X. axonopodis pv. citri strain 306 (Xac), a non-vascular pathogen of citrus, and X. fuscans subsp. aurantifolii strain ICPB10535 (Xfa), a non-vascular pathogen of citrus.

involved in regulation (9 CDSs coding for two-component regulatory systems), in chemotaxis (7 MCPs), in biofilm formation $(x a g B C D$ and a putative filamentous adhesin CDS), and in pathogenicity (T3Es such as xopAF and xopAK) are enriched in the orthologous groups shared between Xff 4834-R and Xoc BLS256. Interstingly, XopAF and XopAK were previously suspected to be involved in tissue specificity of Xoc BLS256 [39]. Orthologs shared by Xff 4834-R and Xoo PXO99A differ significantly in Riley functional classes in comparison to the whole predicted proteomes (calculated $x^{2}=97.88 ; x^{2}{ }_{01}[8]=20.09$ ). CDSs involved in transport and of unknown function were enriched. Further analyses should give information on their putative role in Xanthomonas survival in the vascular system.

Comparison of Xff 4834-R with two citrus pathogens, $X a c 306$ and Xfa ICPB10535, phylogenetically closely related to Xff 4834-R should give insights into functions involved in host specificity and xylem adaptation since both $X a c$ and $X f a$ are not vascular pathogens (Figure 3C). In this comparison, CDSs specific of Xff 4834-R show a distribution in Riley functional classes significantly different (calculated $\mathbf{X}^{2}=1479.39 ; \mathbf{X}^{2}{ }_{01}[8]=20.09$ ) from their distribution in the whole genome and include numerous CDSs of unknown function $(67.3 \%$ of the specific CDSs compared to the $26 \%$ of the CDSs of the whole genome), several T3E encoding genes (xopF1, $x о р A M, x о р C 1, x о p F 2, x о р J 2, x о р T$ and $x о p G)$ and a pectate lyase encoding gene. CDSs present in the specific fraction of Xff 4834-R could play a role in host specificity, as shown by the abundance of T3Es in this fraction. Indeed, repertoires of T3Es have been already pointed out as candidate determinants of host specificity in Xanthomonas [18]. Further studies of CDSs specific of Xff will confirm if some candidates are involved in bean colonization.

\section{Xanthomonads core functions are conserved in Xff 4834-R genome}

Xff 4834-R is fully equipped for sensing the environment

Bacteria mainly detect environmental signals through Methylaccepting Chemotaxis Proteins (MCPs) and sensors of Two-Component Regulatory System (TCRS). MCPs are the principal components of the chemotaxis system. These transmembrane chemoreceptors direct cell locomotion by regulating the histidine kinase CheA, 
which in turn communicates the information to the flagellar motor by phosphorylating its cognate response regulator CheY. In Xanthomonas, most MCPs are clustered in a region dedicated to chemotaxis and motility [42]. This cluster is highly similar within Xanthomonas with the exception of $X$. albilineans, which presents a reduced number of genes encoding MCPs [55]. Twelve MCPs are scattered on the chromosome of Xff 4834-R, among which eleven are also present in $X c v$ 85-10 and in most other Xanthomonas. The minor differences among Xff 4834-R and other Xanthomonas chemotaxis clusters concern the absence of XAC1897 and XCV1938 orthologs in Xff 4834-R genome.

TCRSs are major signal transduction pathways allowing bacteria to adapt to changing environmental conditions. A typical TCRS consists in a membrane-bound sensor histidine kinase (HK) that perceives external stimuli and a cognate response regulator (RR) that mediates the cellular response. Signal is transduced by successive phosphorylation reactions, as for chemotaxis [56]. The high number of TCRSs in Xanthomonas spp. confers to these bacteria a good adaptive potential compared to other bacteria [57-59]. Xff 4834-R genome is composed of 122 putative TCRSs according to their InterPro domains and using criteria defined in previous studies [58-60], including 38 transmembrane sensors, 21 sensor/regulator hybrids (Hy-HKs) and 63 RRs. The number of Xff 4834-R TCRSs (122) is similar to that of Xcv 85-10 (121) Sixty-two TCRSs correspond to pairs of sensor and cognate RR. Such an organization by pair is common in Xanthomonas and acquisition or loss is reported to occur for both elements at the same time, reflecting a probable process of co-evolution [58].

\section{Xff 4834-R is fully equipped for biofilm formation and multiple stress resistance}

Biofilm formation allows bacteria to resist multiple stresses and requires, at least, attachment of cells and production of exopolysaccharide matrix. These individual characteristics also participate in bacterial virulence. Type IV pilus (T4P) is known to mediate a large array of functions, including twitching motility, adhesion, microcolony formation, and virulence factors [61]. Twitching motility occurs through extension, attachment, and then retraction of the T4P. The T4P of Xff 4834- $\mathrm{R}$ is encoded by a large number of genes grouped in clusters scattered all over the genome with 24 out of 32 genes grouped in four main clusters. Xff 4834-R T4P belongs to T4a family, which is structurally related to type 2 secretion system (T2SS) [62]. The major pilin subunit pilA, as well as three pilA-related and one putative minor pilin subunit pilE genes are identified in Xff 4834-R genome. While synteny and identity are conserved for most genes involved in T4P synthesis among Xanthomonas, pilQ of
Xff 4834- $\mathrm{R}$ is disrupted by a frameshift (Additional file 3). Since PilQ is essential for type IV pilus secretion across outer membrane [63-65], it is tempting to speculate that the T4P of Xff 4834-R is unfunctional. However, the truncated PilQ of Xff 4834-R still contained a secretin domain (IPR011662) according to Interproscan software, thus suggesting that PilQ could still be functional in Xff 4834-R. This is in agreement with our previous study, which show that T4P should be functional in Xff 4834-R [16]. Indeed, a mutant deleted in pilA displayed altered adhesion capacities on bean seeds relative to wild-type 4834- $\mathrm{R}$, and a decreased aggressiveness. Therefore either the frameshift observed in pilQ has no major consequences on the protein function, or alternative secretins such as $\mathrm{XpsD}$ and or $\mathrm{XcsD}$ are recruited.

Bacterial attachment, the first step of biofilm formation, depends mainly on adhesion factors such as T4P, Type 1 pilus, and non-fimbrial adhesins. Xff 4834-R genome possesses a cluster of genes encoding a Type 1 pilus, belonging to $\gamma 1$ fimbrial clade of the Chaperon-Usher system [66] and sometimes referred to as Type 7 secretion system [67]. This cluster (XFF4834R_chr30690- XFF4834R_chr30740) is highly similar to that of Xac 306 with two genes encoding the putative pili assembly chaperones, two genes encoding candidate structural fimbrial subunits containing each a spore coat U domain (IPR007893), and one gene coding a predicted usher protein, i.e. an outer membrane protein corresponding to the assembly platform. A conserved secreted hypothetical protein (XFF4834R_chr30730) is also predicted in this cluster as in Xcc ATCC33913 genome, i.e. between one gene coding a candidate structural fimbrial subunit and a putative pili assembly chaperone at the end of the cluster.

To date, the only identified non-fimbrial adhesins in xanthomonads are those secreted through one of the three Type 5 Secretion System (T5SS) subtypes: (i) monomeric autotransporters (T5aSS) [68], (ii) trimeric autotransporters or oligomeric coiled-coil adhesins (T5bSS) [69,70], and (iii) two-partner secretion systems including filamentous hemagglutinins (T5cSS) [71]. A total of nine adhesins potentially secreted by each of these subtypes are predicted in Xff 4834-R genome. The pattern of non-fibrillar adhesins encoded in Xff 4834-R genome is highly similar to that of Xac 306 [72] with two hemagglutinin-like YapH being monomeric autotransporters (encoded by XFF4834R_chr22670, XFF4834R_chr42170), two trimeric autotransporters homologous to YadA (XFF4834R_ chr34400, XFF4834R_chr34420), one hemolysin called FhaC (XFF4834R_chr19440), and three filamentous hemagglutinins secreted through the two-partners pathway (XFF4834R_chr19450, XFF4834R_chr39820, XFF4834R_chr 39830). One putative hemagglutinin (XFF4834R_chr19550), highly similar to HecA, may be non-functional as a frameshift was confirmed in the $\mathrm{C}$-ter part of the predicted 
peptide (Additional file 3). Functional evidence of the involvement in in vitro or in planta adhesion, biofilm formation, and virulence so far has been obtained for four of these non-fibrillar adhesins: YapH (XFF4834R_chr22670), XadA1 (XFF4834R_chr34400), XadA2 (XFF4834R_chr34420), and FhaB (XFF4834R_chr19450) [16]. They participate in the initial adhesion, three-dimensional structure of the biofilm and as a result, in the epiphytic fitness of the bacterium. A role of anti-virulence factor has been proposed for $\mathrm{YapH}$ in order to explain the higher aggressiveness of the mutant deleted of YapH in bean [16].

Exopolysaccharide (EPS) of Xanthomonas are mainly composed of xanthan, polymers of pentasaccharide repeating unit structures carrying at the non-reducing glucose residue a trisaccharide side-chain of varying extent of acylation [73]. Xanthan gum is the predominant component of the extracellular slime [74], a major component of the biofilm [75]. EPS are considered as determinants of disease as they induce the water-soaking in the intercellular space [76] and participate in wiltinduction for vascular pathogens [77]. Involvement in epiphytic fitness of strains belonging to various pathovars has also been demonstrated [78,79]. Xanthan is encoded by a cluster of 12 gum genes, gumBCDEFGHIJKLM [80]. In Xff 4834-R, the gum cluster (XFF4834R_chr26110 to XFF4834R_chr26220) is syntenic with those found in other Xanthomonas such as $X c v$ 85-10. A single nucleotide insertion in position 844 in $g u m N$ modifies the reading frame. In consequence, the TraB domain of the predicted protein is 60 aa truncated compared to functional orthologs in Xanthomonas sp. The 119 aa sequence in the C-terminal part of the predicted protein differs from those of the functional orthologs and is 59 aa longer than for other GumN predicted proteins in Xanthomonas sp. The gene gumN is also fragmented in $X c v$ 85-10 following the insertion of IS1477. In Xoc BLS256, a single base-exchange created a stop codon in the sequence resulting in two peptides (132 and 178 aa). Despite the co-transcription of gumN together with gumB-gumM operon in X. oryzae pv. ory$z a e$ [81], the role of $g u m N$ in xanthan biosynthesis is not demonstrated. The smooth aspect of Xff 4834-R colonies is consistent with a non-altered production of EPS. Pseudogenization of gumN had occurred independently in strains as different as Xcv 85-10, Xoc BLS256 and Xff 4834-R. This raises the question of the involvement of this gene product in the bacterial cycle?

Other genes, such as $x a n A$ (XFF4834R_chr34730) and $x a n B$ (XFF4834R_chr34740), also involved in xanthan biosynthesis [80,82], are present in Xff 4834- $\mathrm{R}$ as is the recently described $x a g A B C$ operon (XFF4834R_chr34180 to XFF4834R_chr34200) [83]. Nevertheless, it should be noted that this latter cluster may not be functional in Xff $4834-\mathrm{R}$ as the first gene of the operon, $x a g A$, is pseudogenized by an early stop codon at its two third of its length. In other Xanthomonas, the xagA gene is highly similar to that found in Xcc 8004 [83]. The pgaABCD operon of Escherichia coli (equivalent to the hmsHFRS of Yersinia pestis) is another operon known to be involved in the synthesis of polysaccharides. Homologs of these genes are found in Xff 4834-R genome (XFF4834R_chr19430 to XFF4834R_chr19470) and in Xac 306 but not in Xcv 85-10 neither in X. campestris genomes. Both the PgaABCD of E. coli and the HmsHFRS of $Y$. pestis are known to be involved in the synthesis of polysaccharide adhesins required for biofilm formation $[84,85]$. The role of these various genes in EPS biosynthesis and pathogenicity of Xff 4834-R remains to be investigated.

\section{The lipopolysaccharide of Xff 4835-R and the genomic plasticity of the O-antigen encoding genes}

Lipopolysaccharide (LPS) is one of the major components of the outer membrane (OM) of Gram-negative bacteria. This essential component confers peculiar permeability barrier properties to the OM, protecting bacterial cell from many toxic compounds. LPS is also known to interact with host cells, inducing innate immunity in both plant and animal host [86]. LPS is an amphipathic molecule consisting of a hydrophobic glycolipid anchor termed lipid A, a hydrophilic polysaccharide portion in the core region and the $\mathrm{O}$-antigen polysaccharide chain [87]. CDSs (lpsJI, xanAB and ugd2) involved in the biosynthesis of LPS precursors are clustered, except pgi and galu that are dispersed in the genome $[80,88]$. The cluster $\operatorname{rmlABCD}$, which contributes also to the biosynthesis of the LPS carbohydrate precursors [80], is located downstream of ugd2 in Xff 4834-R. The biosynthesis of the core-lipid A complex requires the convergent biosynthetic pathways of Kdo2-lipid A portion of LPS and of LPS outer-core involving nine and four genes, respectively [89], all present on the Xff 4834-R chromosome. The eight CDSs involved in the assembly and transport of LPS in Gram-negative bacteria [80,87-89] are also present in Xff 4834-R genome (lptABCDEFG and $m s b A$ ).

The genomic plasticity associated with the O-antigen cluster is in accordance with previous comparative genomic studies $[55,90]$ and might be due to intense diversifying selection and/or to HGT. Indeed, genes involved in $\mathrm{O}$-antigen synthesis are present in a highly variable gene cluster and can be classified into three different groups: (i) O-unit-processing genes, (ii) genes involved in the synthesis of nucleotide sugars specially used as O-antigen residues, and (iii) genes encoding sugar transferases [91]. As in few strains of E. coli, Xanthomonas strains seem to process $\mathrm{O}$-units via an $\mathrm{ABC}$ transporter pathway that involves Wzt and Wzm [90]. However, Wzt and Wzm 
homologs in Xanthomonas strains display considerable variation ranging from 23 to $92 \%$ identities at the amino acid level, which is not in accordance with the phylogenetic relationships of the strains. Furthermore, the Xff 4834-R genes of the $\mathrm{O}$-antigen precursors gmd and $r m d$ are only shared with $X$. axonopodis pv. malvacearum, $\mathrm{Xg}$ ATCC19865, Xcc ATCC33913 and Xcv 85-10. Distribution of sugar transferase genes is even more diverse in Xanthomonas strains. For instance, the bifunctional glycosyl transferases encoded by $w b d A 1$ and $w b d A 2$ has only true orthologs in $X f a, X$. axonopodis pv. malvacearum, $X$. citri pv. mangiferaeindicae and Xcv 85-10. In addition, five genes (XFF4834R_chr34820 - XFF4834R_chr34860) are only shared with $X$. axonopodis pv. malvacearum and Xal GPE PC73. The homology of several contiguous CDSs of Xff 4834-R with those of Xal GPE PC73, which is not a closely related organism, may be indicative of an HGT event.

\section{Nutrient acquisition and utilization}

TonB-dependent transporters (TBDTs) are bacterial outer membrane proteins that allow active high affinity transport of large substrate molecules, among which iron-siderophore complexes, vitamin $\mathrm{B} 12$, and various carbohydrates [92-95]. TBDTs must interact with an inner membrane protein complex consisting of TonB, ExbB, and ExbD to get the proton motive force across the inner membrane to transport substrates [96]. The genome sequence of Xff 4834-R reveals a high number of TBDTs (70 including four pseudogenes and five CDSs with missing or incomplete functional domains) encoding genes. Such an overrepresentation of TBDTs is common in Xanthomonas sp. [93]. None of the TBDTs is specific of Xff 4834-R. Most Xff 4834-R TBDTs have orthologs in Xac 306 and many of them are conserved in xanthomonads, having also orthologs in Xcc ATCC33913. In Xcc ATCC33913, several TBDTs are part of CUT (Carbohydrate Utilization with TBDT) loci comprising also inner membrane transporters, degrading enzymes, and transcriptional regulators [93]. A CUT locus involved in sucrose utilization [93] is well conserved in Xff 4834-R. A second CUT locus, involved in the utilization of $\mathrm{N}$-acetylglucosamine (GlcNac) containing substrates [97], is almost complete in Xff 4834-R, except for the TBDT encoding gene nixC, which is a pseudogene. However, this latter CUT system could be functional as orthologs of three other TBDT encoding genes are present, namely $n i x A$, nixB and $n i x D$. Furthermore, orthologs of two other TBDTs associated with GlcNac in Xanthomonas are also present in Xff4834-R genome, naxA and naxB corresponding to XFF4834R_chr14600 and XFF4834R_chr14590, respectively.

Finally, the four main CUT loci involved in plant xylan scavenging described in Xcc ATCC33913 are conserved in Xff 4834-R genome [98] The main loci involved in xylan utilization, namely $x y t A, x y l R, x y t B$ and $x y l E$ loci, contain genes with putative functional orthologs in Xff 4834-R. The only exception is an alpha-D-glucuronidase encoding gene, which is a pseudogene in Xff 4834-R (XFF4834R_chr41020 agu67A). Diversity in depolymerizing enzyme gene content within CUT loci among strains having different host range may reflect their adaptation to various host plant carbohydrates.

\section{Regulation of virulence factors}

DSF cell-cell signaling pathway is involved in the regulation of many virulence factors such as EPS synthesis, type III secretion, extracellular hydrolytic enzymes [99] and in the reversion of pathogen-induced stomatal closure [100]. This pathway involves a small diffusible signal factor (DSF), the DSF synthetase RpfF and a TCRS RpfC/RpfG [99]. DSF signaling is tightly linked to the intracellular second messenger cyclic dimeric GMP (c-di-GMP) [101,102]. This major gene cluster comprises nine genes in Xcc 8004 [103], while only eight are predicted in Xff 4834-R. Indeed, rpfI which encodes a regulatory protein in Xcc [99] is lacking. This is also the case in Xcv 85-10, while in Xac 306 both rpfH and rpfI are lacking [42]. Xylella fastidiosa shows a partial rpf cluster, which nevertheless plays a key role in regulation and pathogenicity [104]. Mutation of rpfI does not significantly reduce the virulence of Xoo KACC10859 [105]. The rpf pathway is functional in Xff 4834-R and as expected an rpfF mutant shows an altered EPS production and displays rough colonies (our unpublished data).

Another diffusible signal molecule, DF, which was originally identified in $X$. campestris, was shown to be required for the production of xanthomonadin, EPS, systemic invasion, and $\mathrm{H}_{2} \mathrm{O}_{2}$ resistance, which are various biological processes that are crucial for bacterial survival and virulence [106,107]. DF is encoded by $x a n B 2$ [108], a gene belonging to the xanthomonadin biosynthesis pig gene cluster [109], which was recently described as encoding a bifunctional chorismatase that hydrolyses chorismate into 3-hydroxybenzoic acid (3HBA), the DF factor, and 4-HBA [110]. A xanB2 mutant of Xff 4834-R presents, as expected, white colonies proving that the DF system is functional and involved in xanthomonadin production in this strain (data not shown). Biosynthesis of xanthomonadins is encoded by the pig cluster comprising about $20 \mathrm{CDSs}$, which may constitute part of a novel type II polyketide synthase pathway [110]. This pig cluster including $x a n B 2$ is highly conserved among Xanthomonas [110] and Xff 4834-R did not depart from this rule. Gene content is highly conserved between Xoo PXO99A and Xff 4834-R, with the exception of orthologs to PXO_03724 and PXO_03725 (XFF4834R_chr40750 and XFF4834R_ 
chr40740, respectively), which are located $133 \mathrm{~kb}$ away from the pig cluster. The yellow-pigmented colonies of Xff 4834-R prove that this system is functional.

\section{Genes encoding the six types of protein secretion systems are conserved in Xff 4834- $R$}

Gram-negative bacteria use various basic pathways to secrete proteins, among which virulence factors, and target them to the proper compartment. Type I, III, IV, and VI secretion systems (T1SS, T3SS, T4SS, and T6SS) allow translocation of unfolded proteins directly from the cytoplasm to the outside or directly into the host cell cytoplasm. Pathways that translocate polypeptides across the cytoplasmic membrane include general secretory (Sec) and twin-arginine (Tat) pathways. Type II and V secretion systems (T2SS and T5SS) allow crossing the outer membrane from the periplasm. Genes encoding these six secretion systems have been identified in xanthomonads strains so far sequenced [15,55,111].

The T1SS exports in a single step to the extracellular medium a wide range of proteins of different sizes and activities such as pore-forming hemolysins, adenylate cyclases, lipases, proteases, surface layers, and hemophores [112]. The T1SS consists in three proteins: an inner membrane ATP binding cassette $(\mathrm{ABC})$ protein, a periplasmic adaptor also named membrane fusion protein (MFP), and an outer membrane (OMP) channel of the TolC family. Two sets of genes encoding an ABC transporter, a MFP, and an OMP are found in clusters in Xff 4834-R genome (XFF4834R_chr29870 to XFF4834R_chr29890 and XFF4834R_chr24540 to XFF4834R_chr24600), constituting two putative T1SS. Furthermore, the OMP TolC (XFF4834R_chr11840) could be associated to three other putative T1SS composed by sets of genes encoding MFP and ABC transporters (XFF4834R_chr35340 to XFF4834R_chr35370, XFF4834R_chr38590 to XFF4834R_ chr38640, and XFF4834R_chr40790 to XFF4834R_ chr40810). Some T1SS-secreted substrates carry a secretion signal located at the extreme C-terminus [112] and secretion involves a multistep interaction between the substrate and the $\mathrm{ABC}$ protein that stabilizes the assembled secretion system until the C-terminus is presented [113]. One putative substrate of T1SS (XFF4834R chr17340) carrying 2 repetitions of the motif GGXG XDXXX is detected, while 38 other putative substrates carry only one repetition of this motif. The role of Type 1 secreted proteins in Xff 4834-R pathogenicity remains to be demonstrated.

Because of a similarity in the structure of these systems, Multidrug Efflux Systems (MES) are sometimes considered as T1SS [114]. MES are grouped in five families depending on the primary structure and mode of energy-coupling [115]. MES belonging to the resistancenodulation-division (RND) and multidrug and toxic compound extrusion (MATE) families contribute significantly to intrinsic and acquired resistance to antimicrobials, but also to accommodate plant-derived antimicrobials (phytoalexins and isoflavonoids) and hence are of special interest for plant pathogens [116-119]. RND and MATE are secondary transport systems, which utilize an electrochemical gradient of cations across the membrane for drug transport. These MES consist in three components: a RND- or MATEtype exporter protein located in the cytoplasmic membrane, a gated OMP located in the outer membrane, and a MFP that links the exporter protein with the OMP. The drug transport is active and, in RND family, is driven by the proton motive force, while in MATE the drug efflux reaction is coupled with $\mathrm{Na}^{+}$exchange [120]. Xff 4834-R genome contains seven tripartite RND-efflux pump system gene operons. Four other sets of consecutive RND exporter and the MFP coding genes could depend on tolC to assemble MES enabling export of drugs [112]. Two probable MATE transporters, including NorM, are identified in Xff 4834-R genome. In Ralstonia solanacearum, the RND pump AcrA and the MATE pump DinF contribute to its overall aggressiveness, probably by protecting the bacterium from the toxic effects of host antimicrobial compounds [117]. The role of these MES in Xff 4834-R as in other Xanthomonas remains to be analyzed and described. To be secreted through the T2SS and T5SS, proteins are first exported into the periplasmic space via the universal Sec or Tat pathways. The machinery of the Sec pathway recognizes a hydrophobic N-terminal leader sequence on proteins destined for secretion, and translocates proteins in an unfolded state, using ATP hydrolysis and a proton gradient for energy [121]. The tat and the sec genes are highly similar in identity and organization to those found in $X c v$ 85-10 genome. The sec genes are dispersed all over the genome and secM is absent in $X f f 4834-\mathrm{R}$ genome as it is in $X c v$ 85-10. Microsynteny and similar positions on genomes are conserved for the two T2SS (xcs and xps) identified in Xff 4834-R genome with orthologous clusters in $X c v$ 85-10. The T3SS encoded by the hrp gene cluster is a key pathogenicity factor in xanthomonads, with the exception of $X$. albilineans [55]. It is involved in the secretion and translocation of effector proteins directly into the host cell cytoplasm. In Xff 4834-R, the hrp gene cluster is inserted next to an arginine transfer-RNA (tRNA-Arg). One copy of ISXfu2 (see below for ISXfu 2 description) is localized at each side of this cluster, which otherwise is almost identical and syntenic to that of other sequenced Xanthomonas strains (Figure 4). Genes coding the master regulators HrpG (XFF4834R_chr32700) and HrpX (XFF4834R_chr32690) are localized 3.3 $\mathrm{Mb}$ away from the hrp cluster. This type III secretion system was shown to be functional and 


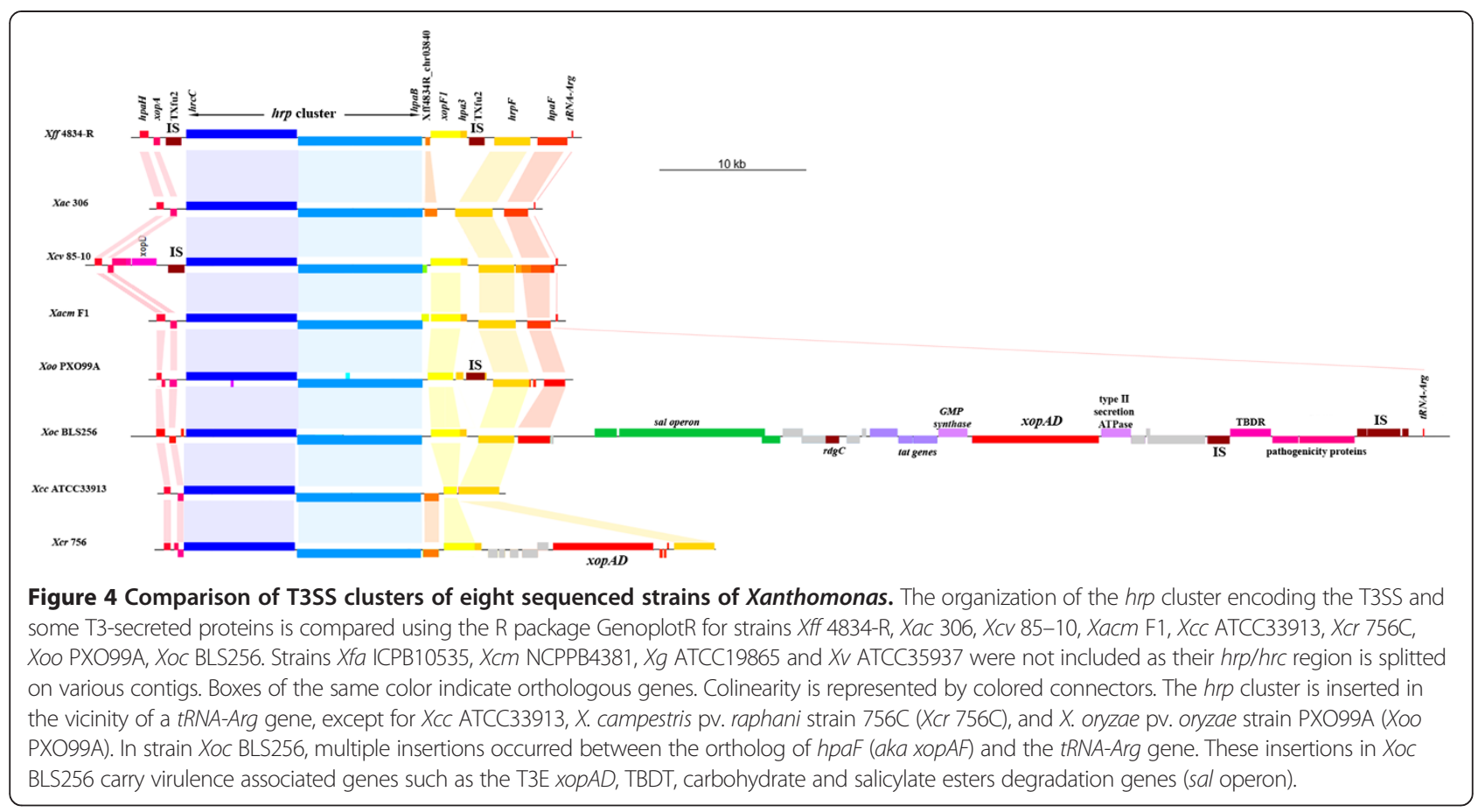

to play a role in the colonization of bean plants and seeds [17].

T4SSs are versatile secretion systems in Gram-negative and Gram-positive bacteria that secrete a wide range of substrates, from single proteins to protein-protein and protein-DNA complexes [122-124]. Many of the T4SSs found in Gram-negative bacteria are similar to that of Agrobacterium tumefaciens, which comprises 12 proteins, named VirB1 to VirB11 and VirD4 [123]. T4SSs have been identified in xanthomonads and have been especially well studied in Xac 306 [125,126]. Two T4SS are present in Xac 306, one found on a plasmid and the second one on the chromosome [125]. Despite the fact that both systems belong to the same P-like T4SS group [127], the two T4SS of Xac 306 do not share either the same genetic organi zation nor high sequence identity at the protein level [125]. In Xff 4834-R, only the chromosomal T4SS is complete. Putative virB5 and virB6 are found on plasmid $\mathrm{b}$ and could be remnants of a plasmidic T4SS.

The T6SS is a recently characterized secretion system that appears to constitute a phage-tail-spike-like injectisome that has the potential to introduce effector proteins directly into the cytoplasm of host cells. It has been identified in many bacteria infecting plants or animals, but also in bacteria found in marine environments, the soil/rhizosphere, and in association (symbiosis, commensalism) with higher organisms [128]. In xanthomonads strains, up to two T6SS clusters have been reported. They are assigned to three different types [46]. Xff 4834- $\mathrm{R}$ contains a single T6SS belonging to the group 3, which presents a kinase/phosphatase/forkhead phosphorylation-type regulator and an AraC-type regulator. This is also the case for $X$. vesicatoria [46].

\section{Xff4834-R displays a large repertoire of CWDEs}

A large repertoire of $\mathrm{T} 2$ secreted degrading enzymes with various activities (i.e. protease, xylosidase, xylanase, pectate lyase, cellulase, polygalacturonase, beta-galactosidase...) is identified in Xff 4834-R genome. These enzymes are suspected to degrade host plant tissues. Orthologs of these 75 secreted enzymes and three pseudogenes are found in the genomes of other Xanthomonas sp., none seeming to be specific of Xff 4834-R. Orthologs of most CWDE described in Potnis et al. [46], or type II secretion substrates described in Szczesny et al. [129] are identified in Xff 4834-R genome. It should be noticed that no orthologs of $x y n C$ (XCV0965), pel3A and pel10A [46], nor of xyn30A, xyl39A and gly43C [98] are found in Xff 4834-R genome and that there are frameshifts in agu67A (XFF4834R_chr41020) and xyn51A (XFF4834R_chr41250). Interestingly, these five latter enzymes have been identified in the xylem-invading bacterium $X c c$. The 1,4- $\beta$ cellobiosidase CbhA is supposed to be required for bacteria to spread within xylem vessels [55]. While Xff 4834-R is known to colonize xylem vessels [6], no ortholog of $c b h A$ has been found in its genome. In most xylem-invading Xanthomonadaceae EngXCA harbors a cellulose-binding domain (CBD) at its C-terminal extremity and a long linker region, which are known to enhance substrate accessibility [130]. Xff 4834-R possesses one gene encoding EngXCA (Xff4834R_chr06240), which however presents apart the CBD domain a relatively short linker domain (19 aa as in Xac 306). Moreover, the orthologs of 
$X$. albilineans genes coding CelS and XalC_0874 present neither long linker regions nor CBD in Xff 4834-R genome. This is also the case for other Xanthomonas [55]. Such differences in depolymerizing enzyme content between these two xylem-invading bacteria (Xcc and X. albilineans) and $X f f$ may reflect a relatively limited ability of Xff to colonize xylem vessels, which is in accordance with infrequent vessel obstructions, necrosis, and wilting symptoms.
Xff 4834-R harbors a specific repertoire of putative T3Es

To mine for the presence of genes coding candidate T3Es (including T3 secreted proteins, T3SPs), we first blasted on the genome of Xff 4834-R the sequence of all known T3Es genes listed on the Xanthomonas.org website. Such a mining of the genome of Xff 4834-R predicts 29 genes encoding T3E orthologs (Table 3), thereby revealing a T3E repertoire larger than previously described

Table 3 List of T3Es and T3SP identified in Xff 4834-R genome and their characteristics

\begin{tabular}{|c|c|c|c|}
\hline T3E / T3SP & Synonyms & Function / features & $\begin{array}{l}\text { Flanking sequences: } \\
\text { IS, ARNt integrase }\end{array}$ \\
\hline
\end{tabular}

Located on the chromosome

\begin{tabular}{|c|c|c|c|c|c|}
\hline AvrBs2 & . & Glycerophosphoryl diester phosphodiesterase & XFF4834R_chr00460 & 63.60 & integrase \\
\hline XopA & Hpa1/HpaG & "Harpin," & XFF4834R_chr41750 & 60.00 & IS4 \\
\hline XopAD & & SKWP repeat protein & XFF4834R_chr40870 & 66.40 & no \\
\hline XopAE & $\mathrm{HpaF/HpaG}$ & LRR protein & XFF4834R_chr38990 & 63.60 & tRNA-Arg \\
\hline XopAF & AvrXv3 & Unknown & XFF4834R_chr42650 & 49.00 & transposase mutator type \\
\hline XopAK & & Unknown & XFF4834R_chr35620 & 58.60 & no \\
\hline XорАM & . & Unknown & XFF4834R_chr33550 & 65.30 & no \\
\hline XopC2 & . & Haloacid dehalogenase-like hydrolase & XFF4834R_chr33300 & 63.20 & no \\
\hline XopE1 & AvrXacE1 & Putative transglutaminase & XFF4834R_chr02600 & 63.40 & no \\
\hline XopF1 & Hpa4 & Unknown & XFF4834R_chr03180 & 63.60 & no \\
\hline XopF2 & . & Unknown & XFF4834R_chr18460 & 63.30 & no \\
\hline XopG & . & M27-family peptidase (Clostridium toxin) & XFF4834R_chr10930 & 51.10 & mutator type transposase \\
\hline Xopl & . & F-box protein & XFF4834R_chr07620 & 65.10 & no \\
\hline XopJ5 & AvrXccB & $\begin{array}{l}\text { Putative C55-family cysteine protease or Ser/Thr } \\
\text { acetyltransferase (Clan CE) }\end{array}$ & XFF4834R_chr16310 & 59.40 & no \\
\hline XopK & . & Unknown & XFF4834R_chr15450 & & no \\
\hline XopL & XAC3090 & LRR protein & XFF4834R_chr15400 & 61.90 & no \\
\hline XopN & . & ARM/HEAT repeat & XFF4834R_chr18430 & 63.30 & no \\
\hline XopP1 & . & Unknown & XFF4834R_chr33320 & 61.60 & no \\
\hline XopP2 & - & Unknown & XFF4834R_chr33310 & 60.10 & no \\
\hline XopQ & . & Putative inosine-uridine nucleoside $\mathrm{N}$-ribohydrolase & XFF4834R_chr42130 & 67.50 & no \\
\hline XopR & . & Unknown & XFF4834R_chr25420 & 66.50 & no \\
\hline ХopT & . & Unknown & XFF4834R_chr23790 & 64.60 & $\begin{array}{l}\text { IS3/IS911; transposase } \\
\text { mutator type }\end{array}$ \\
\hline XopV & . & Unknown & XFF4834R_chr42980 & 62.90 & no \\
\hline XopX & & Unknown & XFF4834R_chr42980 & 65.60 & no \\
\hline XopZ & . & Unknown & XFF4834R_chr21120 & 65.50 & recombination factor rarA \\
\hline \multicolumn{6}{|c|}{ Located on plasmids } \\
\hline XfuTAL1 & "Pth, TAL" & $\begin{array}{c}\text { AvrBs3/PthA-type transcription activator; } 31,5 \text { repeats } \\
\text { of } 34 \text { aa. RVDs: NI NN NN HD NI HD HD HD HD HD NI } \\
\text { NG NI NG NI NN NG NN HD HD NF HD NI HD HD } \\
\text { HD HD HD NG NG }\end{array}$ & XFF4834R_plb00200 & 66.80 & $\begin{array}{l}\text { IS3; ISXac2; Tn3 fragment; } \\
\text { ISXco11; IS3/IS911 }\end{array}$ \\
\hline XfuTAL2 & "Pth, TAL" & $\begin{array}{c}\text { AvrBs3/PthA-type transcription activator; } 16,5 \text { repeats } \\
\text { of } 34 \text { aa. RVDs: NI NG HD NG HD NI NG NI HY NN } \\
\text { N- HD NG HY NN HD NG }\end{array}$ & XFF4834R_pla00470 & & \\
\hline XopC1 & & $\begin{array}{c}\text { Phosphoribosyl transferase domain and haloacid } \\
\text { dehalogenase-like hydrolase }\end{array}$ & XFF4834R_plb00200 & 47.80 & Tn3 fragment; ISXco 11 \\
\hline XopE3 & AvrXacE2 & Putative transglutaminase & XFF4834R_plb00200 & 59.40 & Tn3 fragment; ISXcol1 \\
\hline
\end{tabular}


[18]. Most genes encoding T3Es are located in the chromosome; only 5 genes encoding T3Es are plasmidic (Table 3). As well, a pseudogene similar to the 5'-end of $x o p F 2$ and an extra pseudogenized version of xopAD may be found on the chromosome. Among the genes encoding T3Es found in the genome of Xff 4834-R, six have orthologs in all sequenced strains of Xanthomonas possessing an hrp-T3SS. Based on such an observation, a core effectome of the genus featuring $x o p N, x o p Q$, $x o p F, x o p X, a v r B s 2$ and $x o p P 1$ can be defined.

Many T3Es are located in the vicinity of various types of mobile genetic elements such as ISs or integrases in Xff 4834-R genome (Table 3). Interestingly, the locus carrying xopG contains numerous ISs on both sides of $x o p G$. This locus is found in the vicinity of tRNA genes. Such genetic organization is also observed in other Xanthomonas genomes including $X c v \quad 85-10$ and $X c c$ B100. Interestingly, in the genome of Xcc 8004, xopG is pseudogenized and only one IS can be found flanking $x o p G$ on one side. In the genome of 4834- $\mathrm{R}$, xopG displays a significant GC bias since the average GC content dropped to $51,1 \%$. The predicted XopG protein belongs to the M27 family of metalloproteases. Two CDSs are located between xopG and ISXfu1. These CDSs display a GC content of 61 and $60 \%$ respectively, which remains lower than the average value in the rest of the genome (65\%). The CDS XFF4834R_chr10940 encodes a putative glyoxalase that may participate in stress resistance. The CDS XFF4834R_chr10950 encodes a protein that shares structural similarity with peptidases from the M48 family. Altogether, this suggests that $x o p G$ is carried by a small pathogenicity island that could be transferred by HGT.

The genome of Xff 4834-R also features a CDS resembling the $\mathrm{N}$-terminal part of $x o p F 2$, right upstream a complete allele of $x o p F 2$. Such CDS may constitute an ORPHET for terminal reassortment of novel T3Es [131]. As well, on the positive strand, CDSs Xff4834R_ chr40850 and Xff4834R_chr40860 encode truncated Cterminal and N-terminal parts of XopAD, respectively. These CDSs are located right upstream a full copy of $x o p A D$. The $\mathrm{N}$-terminal part of XopAD features numerous repeats of a 42-residue motif identified as SKWP repeats. The $\mathrm{N}$-terminal part of the full version of XopAD differs from Xff4834R_chr40860 by three indels covering five entire repeats. On the contrary, CDS Xff4834R chr40850 shares $100 \%$ identity at the amino acid level with the C-terminal part of the full $x o p A D$ copy. Such an observation suggests that CDSs Xff4834R_chr40850 and Xff4834R_chr40860 constitute two functional domains that may evolve separately. The C-terminal part may then be reassorted with various $\mathrm{N}$-terminal parts.

Plant-inducible promoters, also called PIP-boxes, are cis-regulatory motifs recognized by the transcriptional activator HrpX that controls the expression of T3SS and
T3Es [132]. PIP boxes are located between 30 and $32 \mathrm{bp}$ upstream the -10 motif of the promoter [133]. Therefore, to mine for potentially novel candidate T3Es and genes expressed in an hrpX-dependent manner in the genome of Xff 4834-R, we identified the occurrence of the previously described PIP-boxes and -10 motifs [134]. PIP-boxes matching the previously described patterns could be identified upstream xорA, хорAM, хорAF хорЕ1, хорJ2, хорJ5, $x o p K$, and $x o p R$. The putative PIP boxes upstream $x o p A$, $x о p A M, x о p A F, x o p J 2, x o p J 5$, and $x o p R$ were located far upstream the translational start codon of the respective CDS (94 bp, 573 bp, 144 bp, 262 bp and 405 bp respectively, Additional file 4). Such an observation suggests the occurrence of very long 5'-UTRs for these genes, as already observed by Schmidtke et al. [135].

Looking at CDSs downstream putative PIP-boxes may reveal sequences corresponding to yet unidentified T3Es, as well as functions co-regulated with type III secretion (Additional file 4). Among CDS found downstream PIP boxes, CDS XFF4834R_chr23750, encoding a putative Serine/cysteine protease, could be a good candidate T3E. Genes coding for two putative polygalacturonases and a secreted lipase may be found downstreal PIP boxes, suggesting that cell wall degradation is co-regulated with type III secretion. Cell to cell bacterial communication may also be partly co-regulated with the type III secretion. Indeed, the gene $\operatorname{trp} E$ encoding a probable anthranilate synthase component is also found among genes located downstream putative PIP-boxes. The involvement of anthranilate synthases in the production of quorum signals controlling the production of virulence factors was recently documented in Pseudomonas aeruginosa [136].

\section{Eight types of insertion sequences (ISs) are present in Xff 4834-R genome}

A total of 127 IS copies are present in the genome of Xff 4834-R. Among those, only 79 appear to be complete (Additional file 5) and are split into five isoforms: ISXax1 [137], ISXfu1 (https://www-is.biotoul.fr// accession number: FO203524), ISXfu2 (https://www-is.biotoul.fr// accession number: FO203525), ISXcd1 (AF263433), and ISXac2 [42], and three types of degenerated ISs (belonging to IS3-, IS5-, and IS1595- families) [137]. ISXfu1 has not yet been identified in any other sequenced genome but an isoform was previously sequenced (accession number: AY375317) from another bean-associated xanthomonads strain. There are 26 insertions or remnants of ISXfu1 found all over Xff 4834- $\mathrm{R}$ chromosome, none are plasmidic. There are 33 insertions of ISXfu2 in Xff 4834-R genome. No complete copy of ISXfu 2 is identified so far in other xanthomonads genomes. However, exact copies of the transposase TXfu2 are present in $X f a$ ICPB10535 translated genome.

Overall, Xff 4834-R contains more ISs than Xac 306 [138] and less ISs than X. oryzae strains [47]. ISXax1 is 
the most abundant IS in Xff 4834-R genome and belongs to IS256-family [137]. Members of this family are plasmidic in Xac 306 and Xcv 85-10 but are present in multiple chromosomic copies in the four sequenced strains of $X$. oryzae [30]. Integration and dissemination of ISXax1 in Xff 4834-R chromosome may have occurred with the partial integration of pXCV38 plasmid (see below).

Furthermore, 12 remnants of ISs belonging to several families are also inserted in Xff 4834-R genome (Additional file 5). These degenerated elements are probably not functional anymore. Most remnants colocalize with other IS elements. These interdigitations of various intact or partial IS elements has been noted repeatedly in the literature [139] This may reflect the scars of consecutive but isolated transposition events resulting from selection for acquisition or loss of accessory genes.

\section{Occurrence of other mobile genetic elements inserted into the chromosome of Xff 4834-R}

Several predicted viral DNA genes and fragments are found all over the genome of Xff 4834-R (Additional file 5). A DNA region of more than 6,500 bp contains 10 CDSs of phage-related proteins including one copy of the $\phi L f$ filamentous phage. The CDS (XFF4834R_chr22400) coding the integrase of the $\phi L f$ phage [140] is disrupted indicating that the protein should not be functional anymore. Two contiguous and symmetric copies of this phage are found in Xcc ATCC33913 genome [141]. In Xff 4834-R downstream of the complete $\phi L f$ insertion, a truncated copy of $\phi L f$ "orf112" is found contiguous to two consecutive insertions of ISXax1. This suggests that ISXaxI insertions could be posterior to $\phi L f$ integration and could have deleted most part of the second $\phi L f$ integration, from which only the truncated "orf112" remained.

In addition, a chromosomal DNA region of more than $30 \mathrm{~Kb}$ contains CDSs that are orthologous to CDSs of plasmidic origin in other Xanthomonas. Half of this region $(17 \mathrm{CDSs})$ is syntenic to a part of $\mathrm{pXcB}$ from $X$. citri pv. aurantifolii strain B69 [142], and 12 CDSs are syntenic to a part of pXCV38 from Xcv 85-10. Some CDSs of these two parts of the native plasmids are orthologous but the copies found in Xff 4834-R genome have higher identities with pXCV38 copies (Additional file 5), suggesting that they originate from pXCV38 rather than $\mathrm{pXcB}$. It is worthwhile to mention that $p t h B$ from $\mathrm{pXcB}$ is not conserved in Xff 4834- $\mathrm{R}$ while its two adjacent CDSs are. This T3E, PthB, is required to cause cankers on citrus $[142,143]$. However, the gene encoding another T3E, xopAF, is inserted in this region together with ISXaxI and ISXfu2. Orthologs of both xopAF and Txfu2 are found by Blastp only in Xfa ICPB10535 genome. The association xopAF-ISXax1 is unique to Xff 4834- $\mathrm{R}$ and is not found in other xanthomonads genomes. ISXax1 is present in the native pXCV38 [137] and hence could have transposed from this plasmid during its integration into Xff 4834-R chromosome.

\section{Mobile genetic elements co-localize with two major chromosomal inversion events, one large DNA deletion event, and various gene insertions}

Half of the IS insertion events are distributed all over the genome while the other insertions are grouped in spots of two to six ISs (Figure 1). This non-random distribution of IS elements is common in bacterial genomes [30]. ISXfu1 is involved in 13 IS hot spots together with ISXax1 and in a lesser extent with ISXfu2 and other IS remnants. Five other IS spots involved only ISXfu2, ISXax1, and IS remnants. Xff 4834-R ISs are associated with two major chromosomal inversion events, one large DNA deletion event, various gene transfers, and several gene breakdowns.

\section{Two major chromosomal inversions co-localize with ISXfu1 and ISXfu2.}

A dramatic pattern of genomic rearrangement consisting in two inversion events involving ISXfu1 and ISXfu2 is revealed by comparison with the most closely related assembled genome (Xac 306 genome) (Figure 5). The combination of various sequencing approaches that we used ensures a high quality of the assembly and we can therefore rule out that such an inversion would originate from an error in the assembly. A considerable colinearity exists among xanthomonads genomes allowing inversion events to be easily detected, as was previously observed between Xcc ATCC33913 and Xcc 8004 [141]. Two copies of ISXfu1 (at positions 2,165,981 and 3,152,577) and two copies of ISXfu2 (at positions 1,270,755 and 3,930,499) flank the inverted segments that are located symmetrically at mirror image positions across the replication axis. Consequently, the GC skew pattern is not altered by these inversions (Figure 1). These inversions result in an inverted order of CDSs and coding strand in Xff 4834-R compared to the other Xanthomonas on the length of these two regions of around $1 \mathrm{Mb}$ each (Figure 5).

\section{A large deletion in the flagellar gene cluster in Xff 4834-R genome is associated with ISXfu2}

Annotation of the flagellum cluster reveals that a group of 34 contiguous genes is lacking in Xff 4834-R genome compared to $X c v 85-10$ genome. Instead of these genes, a complete copy of ISXfu2 is inserted in Xff 4834-R genome (Figure 6). Notably, genes coding for the periplasmic rod and its rings, the hook, and the filament are lacking. These elements are essential for flagellum biosynthesis [144]. As suspected in the absence of a functional flagellum, no swimming motility can be observed for this strain in a soft-agar assay (Figure 7). This is a surprising observation, as xanthomonads are known to 


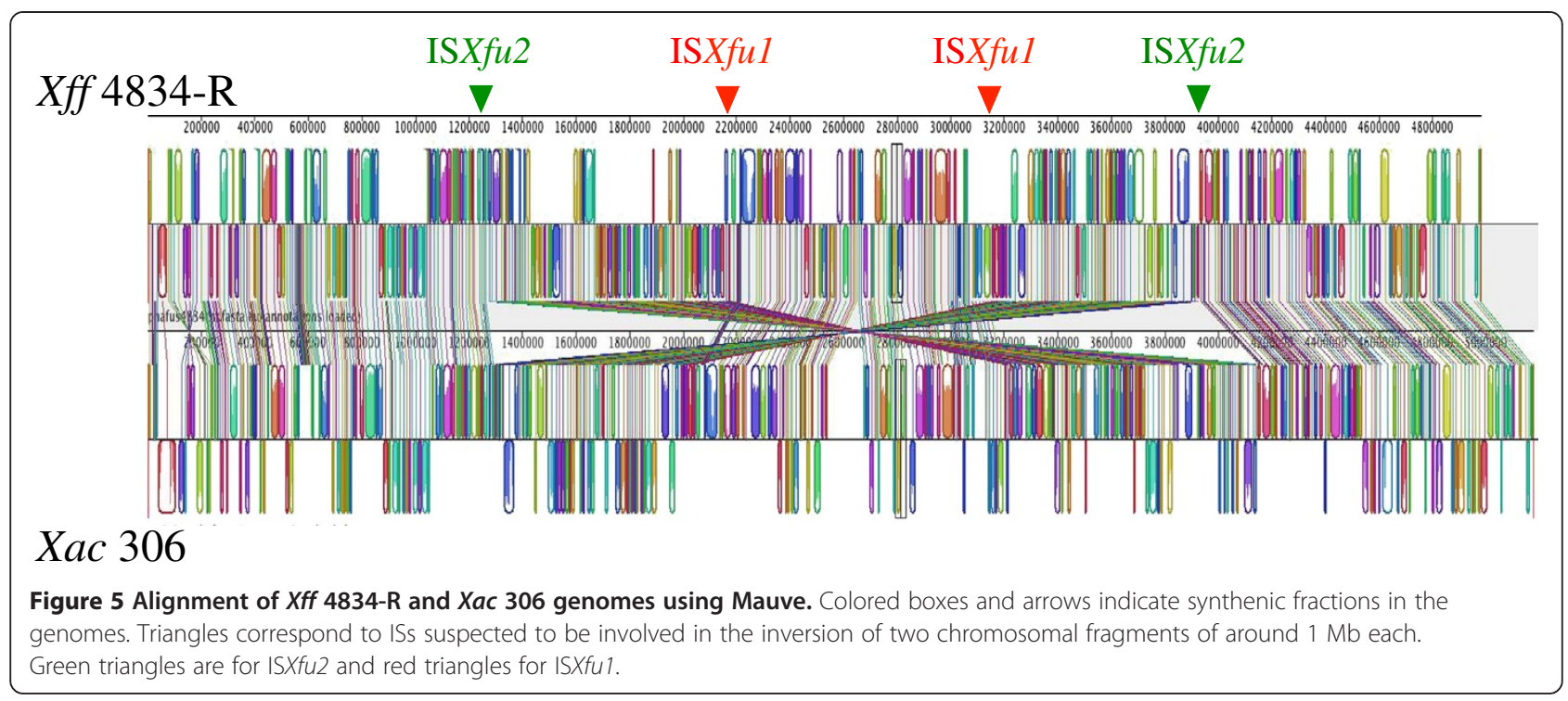

be motile by means of a single polar flagellum [145]. However, as we obtained a high quality fully assembled genome, this fragment absence could not be due to sequencing errors or assembling problems. No such flagellar deletion was observed so far in any other complete assembled genome sequence of any xanthomonads. On the contrary, the flagellar cluster is highly conserved among microbes. In particular, elements such as the Flg22 peptide are usually described as canonical microbial associated molecular patterns (MAMPs) involved in the induction of the first layers of plant defense [146].

Absence of motility is not restricted to the strain Xff 4834-R and involves several species within the Xanthomonas genus To determine if the event leading to a non-functional flagellum system is strain specific, pathovar specific or if, in contrast, it could be observed in other species of the genus, markers of the integrity of the flagellar cluster were searched for in several collections. To do so, seven consensus primers pairs (Additional file 6) were designed and used for PCR-amplification of genes regularly dispersed all over Xcv 85-10 flagellar cluster (Figure 6).

Acollection of 190 strains, mostly type strains representing most species and numerous pathovars within the Xanthomonas genus except CBB agents was intially used. For most strains, signals at the expected sizes were generated indicating that these strains should harbor complete flagellar cluster. However, some PCR were negative for seven strains that belong to six different species (Table 4a). Since several PCR tests were negative in each strain, this strongly indicates that one or several groups of genes could be missing. Different patterns of deletions are observed. Their impact on motility of strains was tested using soft-agar assays. None of these

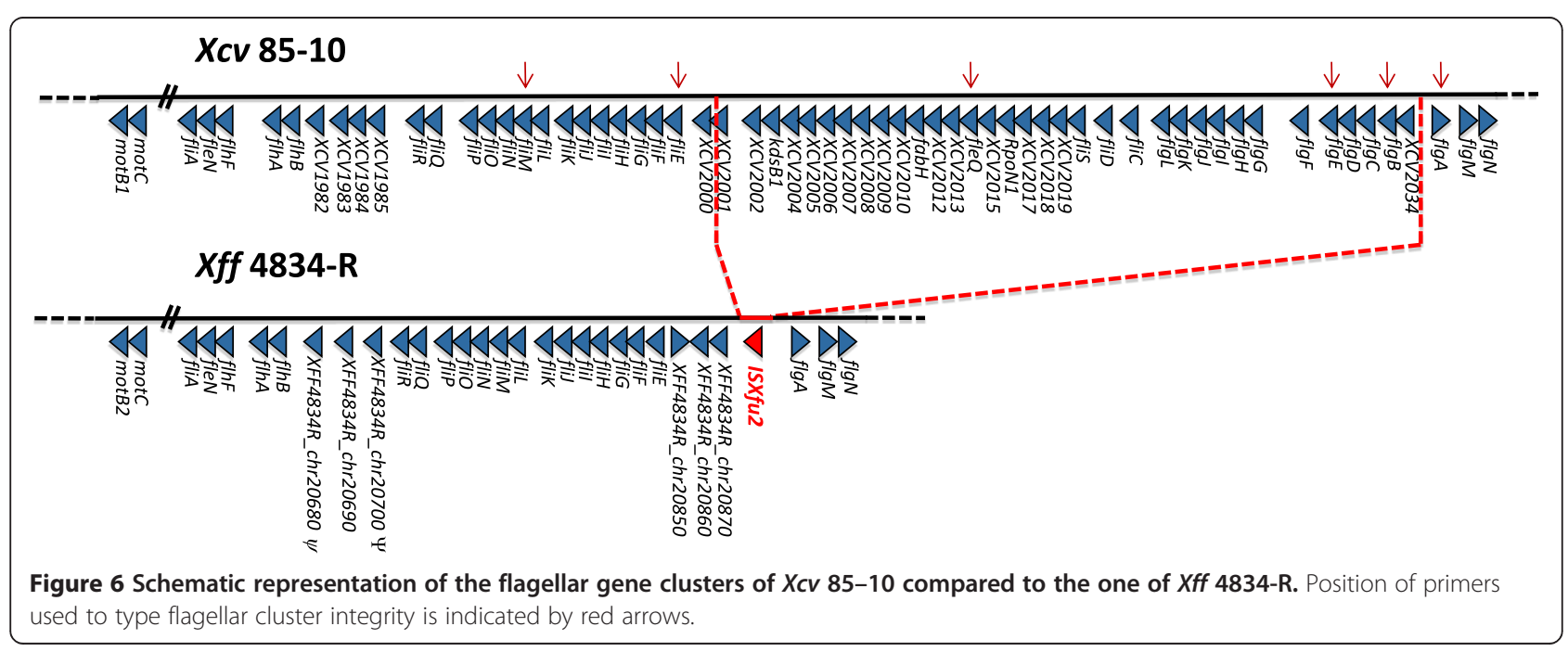




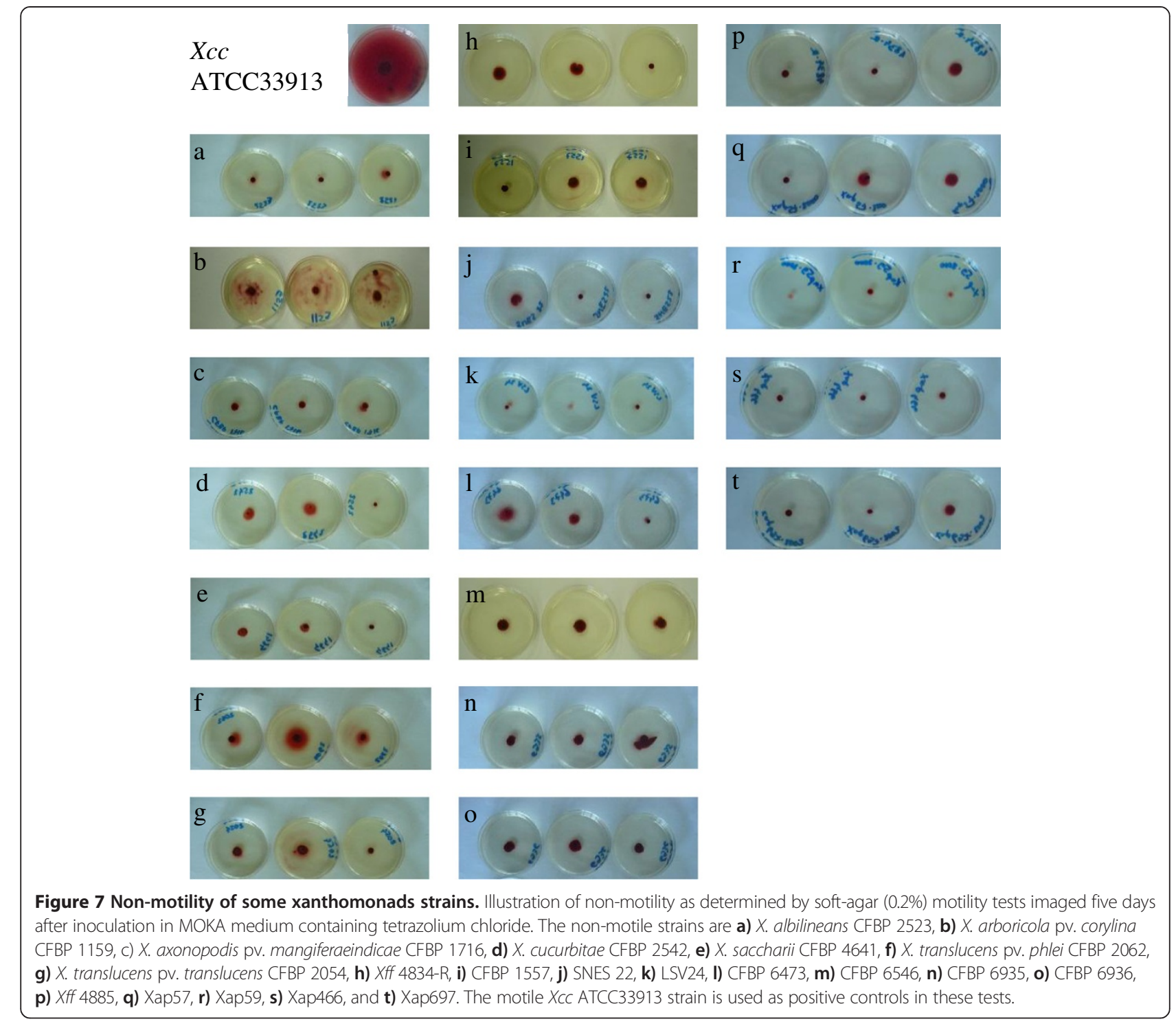

seven strains are motile (Figure 7a to g). Among these, the pathotype strains of $X$. translucens pv. phlei and X. translucens pv. translucens are not motile (Table 4 and Figure $7 \mathrm{f}$ and g). Moreover, the genomes of two strains belonging to $X$. translucens were recently made publicly available and also show partial or entire deletion of the flagellar cluster (Table 5), suggesting that they are also non-motile. The genome of X. translucens pv. graminis ART-Xtg29 has not one single orthologous gene (CDS with more than $80 \%$ identity on more than $80 \%$ of the length) of any gene from Xcv 85-10 flagellar cluster. In the genome of X. translucens pv. translucens DSM 18974, six CDSs from the flagellar cluster-I encoding protein involved in flagellar structure are lacking, thereby probably altering the motility of the strain [147]. The absence of motily could hence occur in a wide range of species or pathovars within the genus Xanthomonas.
Distribution of non-motile strains was also assessed in a collection of 148 strains representing the four genetic lineages ( $X$. axonopodis pv. phaseoli GL1, GL2, GL3, and $X f f)$ of the agents responsible for the common bacterial blight of bean. While $95 \%$ of the strains harbor a complete flagellar cluster, eight strains possess an incomplete flagellar cluster (Table $4 \mathrm{~b}$ ). Three patterns of deletion were identified. One pattern is found in several strains from the GL1 isolated in the Americas over a large period of time and another pattern is found in fuscous strains isolated from different places in France over a period of 30 years. Absence of motility was, once again, confirmed by phenotyping the strains with softagar motility tests (Figure $7 \mathrm{~h}$ to o).

In order to assess the prevalence of non-flagellate strains in natural environments, 12 strains isolated from the same epidemic than Xff 4834-R were screened for 
Table 4 Flagellar cluster integrity in a collection of 338 strains of Xanthomonas spp

\begin{tabular}{|c|c|c|c|c|c|c|c|c|c|c|c|}
\hline \multicolumn{12}{|c|}{ a Xanthomonas collection except common bacterial blight agents } \\
\hline Taxon & $\begin{array}{l}\text { \# or code } \\
\text { of strains }\end{array}$ & $\begin{array}{l}\text { Geographical } \\
\text { origin }\end{array}$ & Host & $\begin{array}{l}\text { Year of } \\
\text { isolation }\end{array}$ & flim & flie & fleQ & flic & flgE & $f l g B$ & $f \operatorname{fg} A$ \\
\hline Xanthomonas spp. & 183 strains & Diverse & Diverse & Diverse & 1 & 1 & 1 & 1 & 1 & 1 & 1 \\
\hline$X$. albilineans & CFBP 2523 & Fidgi Island & Saccharum officinarum & 1961 & 1 & 1 & 1 & 0 & 0 & 0 & 0 \\
\hline X. arboricola pv. corylina & CFBP 1159 & USA & Corylinus maxima & 1939 & 0 & 0 & 0 & 1 & 1 & 1 & 1 \\
\hline X. axonopodis pv. mangiferaeindicae & CFBP 1716 & India & Mangifera indica & 1957 & 0 & 0 & 1 & 1 & 1 & 1 & 1 \\
\hline X. cucurbitae & CFBP 2542 & New-Zealand & Cucurbita maxima & 1968 & 1 & 1 & 0 & 1 & 0 & 0 & 0 \\
\hline X. saccharii & CFBP 4641 & France & Saccharum officinarum & 1980 & 1 & 1 & 0 & 1 & 0 & 0 & 0 \\
\hline$X$. translucens pv. phlei & CFBP 2062 & Switzerland & Phleum sp. & 1978 & 1 & 1 & 0 & 1 & 0 & 0 & 0 \\
\hline$X$. translucens pv. translucens & CFBP 2054 & USA & Hordeum vulgare & 1933 & 1 & 1 & 0 & 1 & 0 & 0 & 0 \\
\hline \multicolumn{12}{|c|}{ b. Common bacterial blight agent collection } \\
\hline Genetic lineage & $\begin{array}{l}\text { \# or code } \\
\text { of strains }\end{array}$ & $\begin{array}{l}\text { Geographical } \\
\text { origin }\end{array}$ & Host & $\begin{array}{l}\text { Year of } \\
\text { isolation }\end{array}$ & flim & flie & fleQ & flic & flgE & $f l g B$ & $f \operatorname{fg} A$ \\
\hline $1,2,3$, fuscans & 140 strains & Diverse & Diverse & Diverse & 1 & 1 & 1 & 1 & 1 & 1 & 1 \\
\hline fuscans & $4834-\mathrm{R}$ & France & P. vulgaris cv. Michelet & 1998 & 1 & 1 & 0 & 0 & 0 & 0 & 1 \\
\hline fuscans & CFBP 1557 & France & P. vulgaris Cv. Michelet & 1974 & 1 & 1 & 0 & 0 & 0 & 0 & 1 \\
\hline fuscans & SNES 22 & France & P. vulgaris cv. Fin de bagnols & 2010 & 1 & 1 & 0 & 0 & 0 & 0 & 1 \\
\hline fuscans & LSV 24 & France & P. vulgaris cv. Suisse blanc & 2005 & 1 & 1 & 0 & 0 & 0 & 0 & 1 \\
\hline fuscans & CFBP 6473 & $N A^{a}$ & $N A^{a}$ & NA & 0 & 0 & 1 & 1 & 1 & 1 & 1 \\
\hline 1 & CFBP 6546 & USA & P. vulgaris & 1978 & 0 & 0 & 0 & 0 & 1 & 1 & 1 \\
\hline 1 & CFBP 6935 & Brazil & P. vulgaris & 1993 & 0 & 0 & 0 & 0 & 1 & 1 & 1 \\
\hline 1 & CFBP 6936 & Brazil & P. vulgaris & 2000 & 0 & 0 & 0 & 0 & 1 & 1 & 1 \\
\hline
\end{tabular}

Strains were chosen to represent various species and pathovars within Xanthomonas. Signal at the expected size for each primer set (1) indicates the presence of the marker, while the absence of PCR signal at the expected size (0) is interpreted as the absence of the gene or allelic diversity and a suspected absence of motility. Absence of motility was confirmed by soft-agar motility test as illustrated in Figure 7.

a Not available.

flagellar cluster integrity and motility. These strains were sampled in the same field than Xff 4834-R (in 1998) and in fields representing the following bean generations (seeds harvested in 1998 field sown in 2000, and seeds harvested in 2000 field plots sown in 2002). About half of the strains isolated each year is mobile, while the other half is not (Table 6, Figure $7 \mathrm{p}$ to $\mathrm{t}$ ). This suggests that two populations are cohabiting in these epidemics, one being flagellate and the other not. This suggests that a non-flagellate strain may be fit in the field, at least in mixed populations with flagellate strains, as it can naturally colonize beans and be seed-transmitted over several generations.

All the non-flagellate strains that lack FliC obviously also lack Flg22. Flg22 is a major MAMP that is recognized by its cognate receptor FLS2, thus activating basic host defense responses. Since natural populations of Xff may be composed of flagellate and aflagellate strains, the size of the population is likely to be underestimated by the plant host due to the lack of recognition of aflagellate strains. Therefore, the Xff population may overcome host defense and more easily invade its host. However, non-functionality of the flagellar cluster is not a frequent event in xanthomonads indicating that absence of motility could be a negative trait. Indeed, chemotaxis plays a major role in virulence of numerous pathogenic bacteria allowing bacteria to gain entry sites $[148,149]$. It is also likely that chemotaxis and motility play a role in fitness of bacteria outside the host, as in water for example. However, very little is known concerning any aspect of xanthomonads life outside their host. Without a functional flagellum, a bacterium cannot rely on chemotaxis to move toward attractants and away from repellants, and cannot locate and infect plant hosts in its natural niches, which could be considered as negative traits in natural environments.

\section{ISXfu2 is flanking the hrp gene cluster on both sides colocalizing with T3E gene insertions}

Breaks in synteny occur on both sides of the hrp cluster, in regions where various genes encoding candidate T3Es may be found. Interestingly, complete copies of ISXfu 2 are located on each side of the hrp cluster of Xff 4834-R. Such a location coincides with loci displaying variations between genomes of Xanthomonas (Figure 4; [46]). Indeed, on one side of the hrp cluster, the locus located 
Table 5 Orthologs of Xcv 85-10 flagellar genes in genomes of xanthomonads

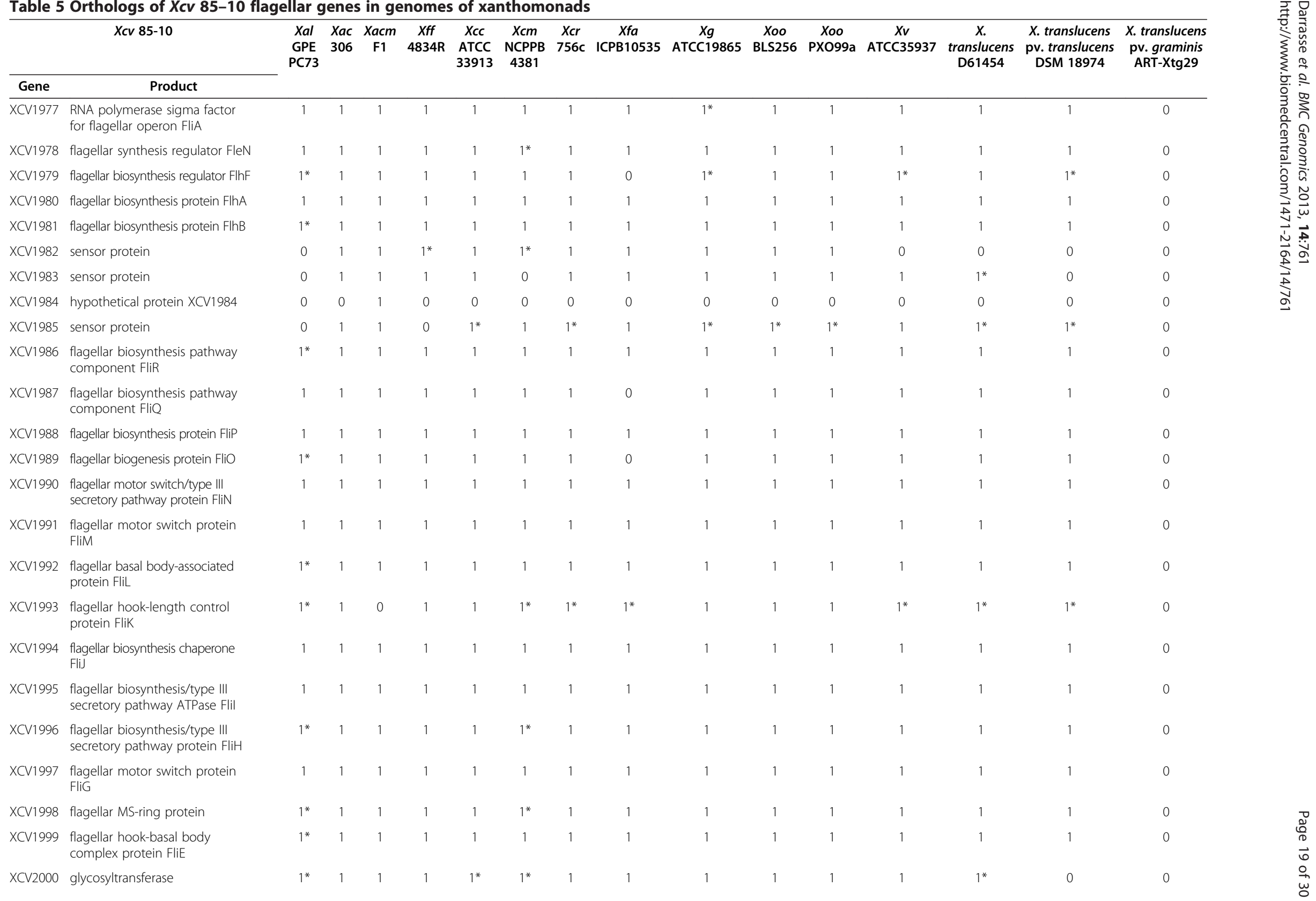


Table 5 Orthologs of Xcv 85-10 flagellar genes in genomes of xanthomonads (Continued)

\begin{tabular}{|c|c|c|c|c|c|c|c|c|c|c|c|c|c|c|c|c|}
\hline XCV2001 & hypothetical protein XCV2001 & 0 & 0 & 0 & 0 & 0 & 0 & 0 & 0 & 0 & 0 & 0 & 0 & 0 & 0 & 0 \\
\hline XCV2002 & hypothetical protein XCV2002 & 0 & 0 & 1 & 0 & 0 & 0 & 1 & 0 & 1 & 0 & 0 & 0 & 0 & 0 & 0 \\
\hline XCV2003 & $\begin{array}{l}\text { 3-deoxy-manno-octulosonate } \\
\text { cytidylyltransferase }\end{array}$ & $1^{*}$ & 0 & 1 & 0 & 0 & 0 & 1 & 0 & 1 & 0 & 0 & 0 & 0 & 0 & 0 \\
\hline XCV2004 & hypothetical protein XCV2004 & 0 & 0 & 1 & 0 & 0 & 0 & 1 & 0 & 1 & 0 & 0 & 0 & 0 & 0 & 0 \\
\hline XCV2005 & hypothetical protein XCV2005 & 0 & $1^{*}$ & 1 & 0 & 0 & 0 & $1^{*}$ & $1^{*}$ & $1^{*}$ & 0 & $1^{*}$ & $1^{*}$ & 0 & $1^{*}$ & 0 \\
\hline XCV2006 & hypothetical protein XCV2006 & $1^{*}$ & $1^{*}$ & 1 & 0 & 0 & $1^{*}$ & $1^{*}$ & $1^{*}$ & $1^{*}$ & $1^{*}$ & $1^{*}$ & $1^{*}$ & $1^{*}$ & $1^{*}$ & 0 \\
\hline XCV2007 & Rieske $2 \mathrm{Fe}-2 \mathrm{~S}$ family protein & $1^{*}$ & $1^{*}$ & 1 & 0 & 0 & $1^{*}$ & $1^{*}$ & $1^{*}$ & $1^{*}$ & $1^{*}$ & $1^{*}$ & $1^{*}$ & $1^{*}$ & $1^{*}$ & 0 \\
\hline XCV2008 & acetyltransferase & $1^{*}$ & $1^{*}$ & 1 & 0 & 0 & $1^{*}$ & $1^{*}$ & $1^{*}$ & $1^{*}$ & $1^{*}$ & $1^{*}$ & 1 & $1^{*}$ & $1^{*}$ & 0 \\
\hline XCV2009 & short chain dehydrogenase & $1^{*}$ & $1^{*}$ & 1 & 0 & 0 & $1^{*}$ & $1^{*}$ & $1^{*}$ & $1^{*}$ & 1 & $1^{*}$ & 1 & $1^{*}$ & 0 & 0 \\
\hline XCV2010 & short chain dehydrogenase & 1 & $1^{*}$ & 1 & 0 & 0 & $1^{*}$ & $1^{*}$ & $1^{*}$ & $1^{*}$ & 1 & $1^{*}$ & 1 & $1^{*}$ & $1^{*}$ & 0 \\
\hline XCV2011 & 3-oxoacyl-ACP synthase & 1 & 1 & 1 & 0 & 0 & 1 & $1^{*}$ & 1 & 1 & 1 & 1 & 1 & 1 & 0 & 0 \\
\hline XCV2012 & acyl carrier protein & 1 & 1 & 1 & 0 & 0 & 1 & 1 & 0 & 1 & 1 & 1 & 1 & 1 & 1 & 0 \\
\hline XCV2013 & aminotransferase & 1 & 1 & 1 & 0 & $1^{*}$ & 1 & 1 & 1 & 1 & 1 & 1 & 1 & 1 & 0 & 0 \\
\hline XCV2014 & $\begin{array}{l}\text { flagellar sigma-54 dependent } \\
\text { transcriptional activator FleQ }\end{array}$ & 1 & 1 & 1 & 0 & 1 & 1 & 1 & 1 & 1 & 1 & 1 & 1 & 1 & 1 & 0 \\
\hline XCV2015 & $\begin{array}{l}\text { two-component response } \\
\text { regulator }\end{array}$ & 1 & 1 & 1 & 0 & 1 & 1 & 1 & 1 & 1 & 1 & 1 & 1 & 1 & 0 & 0 \\
\hline XCV2016 & $\begin{array}{l}\text { RNA polymerase sigma-54 } \\
\text { factor }\end{array}$ & 1 & 1 & 1 & 0 & 1 & 1 & 1 & 1 & 1 & 1 & 1 & 1 & 1 & 1 & 0 \\
\hline XCV2017 & $\begin{array}{l}\text { LuxR family two-component } \\
\text { response regulator }\end{array}$ & 1 & 1 & 1 & 0 & 1 & 1 & 1 & 1 & 1 & 1 & 1 & & 1 & 1 & 0 \\
\hline XCV2018 & hypothetical protein XCV2018 & 0 & 1 & 1 & 0 & 0 & 1 & 1 & 1 & 1 & 1 & 1 & 0 & 0 & $1^{*}$ & 0 \\
\hline XCV2019 & hypothetical protein XCV2019 & 0 & 1 & 1 & 0 & 0 & 1 & 1 & 0 & 1 & 1 & 1 & 0 & 0 & $1^{*}$ & 0 \\
\hline XCV2020 & flagellin-specific chaperone Flis & $1^{*}$ & 1 & 1 & 0 & 1 & 1 & 1 & 1 & 1 & 1 & 1 & 0 & 1 & 1 & 0 \\
\hline XCV2021 & flagellar capping protein & $1^{*}$ & 1 & 1 & 0 & 1 & 1 & 1 & 1 & 1 & 1 & 1 & $1^{*}$ & 1 & $1^{*}$ & 0 \\
\hline XCV2022 & flagellin & $1^{*}$ & 1 & 1 & 0 & 1 & 1 & 1 & 1 & 1 & 1 & 1 & 1 & 1 & 1 & 0 \\
\hline XCV2023 & $\begin{array}{l}\text { flagellar hook-associated protein } \\
\text { FlgL }\end{array}$ & $1^{*}$ & 1 & 1 & 0 & 1 & 1 & 1 & 1 & 1 & 1 & 1 & 1 & 1 & 1 & 0 \\
\hline XCV2024 & $\begin{array}{l}\text { flagellar hook-associated protein } \\
\text { Flgk }\end{array}$ & $1^{*}$ & 1 & 1 & 0 & 1 & $1^{*}$ & 1 & 1 & 1 & 1 & 1 & 1 & 1 & $1^{*}$ & 0 \\
\hline XCV2025 & $\begin{array}{l}\text { flagellar rod assembly protein/ } \\
\text { muramidase Flg」 }\end{array}$ & $1^{*}$ & 1 & 1 & 0 & 1 & 1 & 1 & 1 & 1 & 1 & 1 & 1 & 1 & 1 & 0 \\
\hline XCV2026 & $\begin{array}{l}\text { flagellar basal body P-ring } \\
\text { protein }\end{array}$ & 1 & 1 & 1 & 0 & 1 & 1 & 1 & 1 & 1 & 1 & 1 & 1 & 1 & 1 & 0 \\
\hline XCV2027 & $\begin{array}{l}\text { flagellar basal body L-ring } \\
\text { protein }\end{array}$ & 1 & 1 & 1 & 0 & 1 & 1 & 1 & 1 & 1 & 1 & 1 & 1 & 1 & 0 & 0 \\
\hline XCV2028 & $\begin{array}{l}\text { flagellar basal body rod } \\
\text { protein FlgG }\end{array}$ & 1 & 1 & 1 & 0 & 1 & 1 & 1 & 1 & 1 & 1 & 1 & 1 & 1 & 1 & 0 \\
\hline
\end{tabular}


Table 5 Orthologs of Xcv 85-10 flagellar genes in genomes of xanthomonads (Continued)

XCV2029 flagellar basal body rod protein FlgF

XCV2030 flagellar hook protein FlgE

XCV2031 flagellar basal body rod modification protein

XCV2032 flagellar basal body rod protein $\mathrm{FlgC}$

XCV2033 flagellar basal-body rod protein

XCV2034 chemotaxis signal transduction protein

XCV2035 flagellar basal body P-ring biosynthesis protein FlgA

XCV2036 negative regulator of

flagellin synthesis

XCV2037 hypothetical protein XCV2037

* 11

$1 \quad 1^{*}$

$1^{*} \quad 1 \quad 1 \quad 0$

$1^{*} \quad 1-1,0$

$\begin{array}{lll}1 & 1 & 1\end{array}$

$\begin{array}{llll}1 & 1 & 1 & 0\end{array}$

$\begin{array}{lll}1 & 1 & 1\end{array}$

$\begin{array}{lll}1 & 1 & 1 \\ 1 * & 1 & 1\end{array}$

length of the CDS and if the expected functional domains are identified. On other cases, no orthologs are recorded (0).

${ }^{a} \mathrm{X}$. translucens D61454.

b X translucens pv translucens DSM 18974.

${ }^{c}$ X. translucens pv. graminis ART-Xtg29. 
Table 6 Patterns of flagellar clusters in X. fuscans subsp. fuscans strains isolated from successive bean generations

\begin{tabular}{ccccccccc}
\hline $\begin{array}{c}\text { Strain } \\
\text { code }\end{array}$ & $\begin{array}{c}\text { Year of bean } \\
\text { cultivation }\end{array}$ & flim & fliE & fleQ & flic & flgE & flgB & flgA \\
\hline CFBP 4885 & 1998 & 1 & 1 & 0 & 0 & 0 & 0 & 1 \\
Хap57 & 1998 & 1 & 1 & 0 & 0 & 0 & 0 & 1 \\
Хap59 & 1998 & 1 & 1 & 0 & 0 & 0 & 0 & 1 \\
CFBP 4884 & 1998 & 1 & 1 & 1 & 1 & 1 & 1 & 1 \\
Хap45 & 1998 & 1 & 1 & 1 & 1 & 1 & 1 & 1 \\
Хap48 & 1998 & 1 & 1 & 1 & 1 & 1 & 1 & 1 \\
Хap53 & 1998 & 1 & 1 & 1 & 1 & 1 & 1 & 1 \\
Хap62 & 1998 & 1 & 1 & 1 & 1 & 1 & 1 & 1 \\
Хap466 & 2000 & 1 & 1 & 0 & 0 & 0 & 0 & 1 \\
Хap464 & 2000 & 1 & 1 & 1 & 1 & 1 & 1 & 1 \\
Хap697 & 2002 & 1 & 1 & 0 & 0 & 0 & 0 & 1 \\
Хap502 & 2002 & 1 & 1 & 1 & 1 & 1 & 1 & 1 \\
Хap503 & 2002 & 1 & 1 & 1 & 1 & 1 & 1 & 1 \\
\hline
\end{tabular}

Signal at the expected size for each primer set (1) indicates the presence of the marker, while the absence of PCR signal at the expected size (0) is interpreted as the absence of the gene or allelic diversity and a suspected absence of motility. Absence of motility was confirmed by soft-agar motility test as illustrated in Figure 7 .

between $h p a B$ and $h r p F$ carries a copy of ISXfu2 and T3E genes: hpa3 and xopF1. Neither ISXfu2 nor xopF1 and hpa 3 are present in the genome of Xac 306. In Xoo Pxo99, the ISXo8 is located at the same locus as ISXfu 2 in Xff 4834-R. In Xoc BLS256, this locus features a large insertion that carries carbohydrate degradation operons, virulence genes such as the T3E gene xopAD, tat genes, and transposases next to the tRNA-Arg. On the other side of the hrp cluster of Xff 4834-R, another copy of ISXfu2 is located between $h r c C$ and xopA. In Xcv 85-10, IS1595 is located at the same locus, as well as $x o p D$ and two genes coding hypothetical proteins. These observations suggest that in xanthomonads genomes, loci flanking the hrp cluster on both sides are prone to the insertion of mobile genetic elements carrying virulence genes, especially T3Es and behave as PAIs [150].

\section{Gene rearrangements and insertions associated with mobile} genetic elements

Integrons and gene cassette arrays are well known in clinical organisms in which they carry antibiotic resistance genes [151]. Integrons were also described in many bacteria colonizing diverse environments including plants, in which they are supposed to contribute to niche adaptation. Identification of chromosomal integrons in Xanthomonas is based on the presence of a DNA integrase (intI) homolog, a plausible integron-associated recombination site (attI), and a gene cassette array bounded by attC formerly called 59-base element sites. In Xanthomonas, integron chromosomal insertion is located adjacent to the acid dehydratase gene, ilvD [152].
In contrast, the ilvD region in Xff 4834-R contains an IS hot spot (ISXfu2, ISXfu1, and ISXax1) and several genes having no orthologs in other Xanthomonas genomes. However, integron remnants are present elsewhere in Xff 4834-R genome (Additional file 7). A truncated copy of intI is found $2.5 \mathrm{Mb}$ away in Xff 4834-R genome, and adjacent to intI, the attI site flanked by an array of gene cassettes consisting of a single CDS and its attC site [152] In Xcc ATCC33913 integron, several copies of pigH are present in the cassette array. One pseudogenized copy of $p i g H$ is also present in the cassette array of Xff 4834-R. The four other cassettes of this array contain genes encoding cryptic hypothetical proteins. Contiguous to this region, a spot of 4 ISs (ISXax1, ISXcd1, and two copies of ISXfu2) may be involved in the genomic reorganization of $i l v D$ region explaining the different $X f f$ 4834-R integron localizations in comparison to all other sequenced Xanthomonas. In these two regions, different genes with low GC\% and showing no or partial similarities with genes in other Xanthomonas are found together with genes which phylogenies do not follow organism phylogeny (data not shown). This suggests that these genes may have been acquired by IS- and/or integron- promoted HGT.

\section{Most gene pseudogenizations result from indel leading to frameshift and stop codons}

The availability of a deep sequenced and fully assembled genome for Xff 4834-R and of several genomes of closely related organisms gives the opportunity to question pseudogenization. Indeed, comparative genomics is a good mean to identify pseudogenes [153]. In Xff 4834-R genome, the 137 events of pseudogenization observed fall into four cases (Additional file 3). First, fragments of gene for which the mechanism of pseudogenization is not visible anymore could be detected. Fourteen gene fragments initially encoding various functions result from gene erosion by comparison with functional orthologs in other xanthomonads. Among them, $\psi \times x o p F 2$ seems to be a truncated and degenerated copy of xopF2, a T3E encoding gene located downstream. A truncated copy and a complete copy of virB6 gene are also present in the genome of Xff 4834-R. Two truncated copies of virB6 are also present in Xac 306 that both correspond to the N-terminal part of VirB6. Such a process of gene duplication is described to precede pseudogenization or novel function acquisition in various organisms [154]. Second, numerous pseudogenizations are due to CDS disruption by ISs. Fifteen Xff 4834-R pseudogenes belong to this category and most of them affect genes encoding hypothetical proteins, one element of the T4p, and one small remnant of a non-fimbrial adhesin encoding gene (XFF4834R_chr19500). For one of these pseudogenes, a preceding event of gene duplication seems to have 
occurred, as this latter pseudogene is located downstream its putative functional copy $f h a B_{\text {XFF4834R_chr19450, }}$ orthologous to fha $B_{\mathrm{XAC} 1815}$. Third, a sense codon has acquired a point mutation turning it into a stop codon causing premature termination of translation. There are 27 Xff 4834-R pseudogenes concerned by this kind of inframe stop. For 25 of them, a second peptide corresponding to the C-terminal part of the protein can be predicted. RNA sequencing or functional analyses would demonstrate if some of them are still functional and could correspond to the creation of novel genes by fission. Gene fission is already known in the case of modular proteins for which fragments containing functional domain fragments can still be considered as genes. This is the case for some TCRSs [58]. Fourth, most putative pseudogenizations (81 among the 137) found in Xff 4834- $\mathrm{R}$ genome correspond to frameshifted genes consecutive to a short insertion or deletion in the sequence leading to heterologous C-terminal amino acids and/or premature termination of translation (Additional file 3).

\section{A frameshift in hmgA could lead to fuscous pigment production in Xff 4834- $R$.}

A case of pseudogenization by frameshift is particularly relevant in the case of Xff 4834-R, as it explains the abundantly described fuscous phenotype of Xff. Indeed, Xff produce a fuscous pigment due to the disruption of tyrosin catabolism. Secretion and subsequent oxidation of homogentisic acid confers this phenotype to Xff strains [19]. Tyrosine is catabolized as part of normal intermediary metabolism and in the breakdown of external proteins by microorganisms. In order to describe the genetic basis of this specificity of Xff strains compared to most other xanthomonads, we analyzed the tyrosine degradation pathway (http://biocyc.org/META/newimage?object=TYRFUMCAT-PWY). In tyrosine degradation I pathway, tyrosine is converted into fumarate through five reactions. It starts out with the transfer of its amino group to alpha-ketoglutarate by tyrosineglutamate aminotransferase (EC 2.6.1.5). The degradation intermediate of this transaminase reaction is 4hydroxy-phenylpyruvate, which in turn is oxidized in the presence of vitamin $\mathrm{C}$ to homogentisic acid. This reaction is catalyzed by 4-hydroxyphenylpyruvate dioxygenase (EC 1.13.11.27). The ring structure of homogentisate is subsequently broken and the linear C8 unit degraded in two reaction steps to fumarate and acetoacetate, one citric acid cycle intermediate and one ketone body. Based on high sequence similarity with homologs in other xanthomonads, genes of this pathway seem to be functional in the genome of Xff 4834-R, with the exception of $h m g A$, the gene encoding the homogentisate oxygenase. Interestingly, this gene $\Psi$ XFF4834R_chr04450 appears to be non-functional in Xff 4834-R, due to a frameshift at position 920 . Instead of a 458 residues reported for other HmgA, the protein synthetized by Xff $4834-\mathrm{R}$ is 306 aa long. There are no functional orthologs of this gene in Xff 4834-R. Correction of this mutation or complementation of Xff 4834-R strain with a functional allele would definitely proof that in wild type $X f f$ homogentisate could not be degraded in 4-maleylacetoactetate and accumulates giving rise to the brown diffusible pigment of Xff. Indeed, this acid can spontaneously oxidize and polymerize, leading to the formation of pyomelanins [155].

\section{Except for pseudogenes related to HGT events, phylogeny of Xff 4834-R putative pseudogenes follows the phylogeny of the organisms.}

In order to get insights into the pseudogene evolutionary history, we compared the phylogenetic tree of every gene family having a pseudogene in Xff 4834-R with the phylogeny of six housekeeping genes among the 15 genomes used for comparative genomics (Additional file 1). Two pseudogenes (XFF4834R_chr25070 and XFF4834R_ chr25180), located in the integron region (see above), have nucleotidic sequences more closely related to Xcc ATCC33913 than to Xfa ICPB10535 or Xac 306 (Additional file 8). This is consistent with HGT and also with the deleterious impact of integrons on genomes [156]. Moreover, a third pseudogene (XFF4834R_chr33800) has a phylogeny different from that of the organisms. This pseudogene of unknown function is located in the vicinity of ISXaxI and then could have been acquired by HGT. The phylogeny of the other pseudogenes follows the phylogeny of the housekeeping genes reflecting a probable recent pseudogenization (Additional file 8).

\section{Conclusions}

Genomic comparisons and Xff 4834-R genome annotation enlighten features involved in plant pathogenicity and adaptation to different ecological niches. We identified 29 T3Es, including TALEs, depolymerizing carbohydrate enzymes, sensors of TCRS and chemotaxis, TBDT and many proteins of unknown functions that could be involved in bean adaptation, colonization of xylem and other niches, the role of which remains to be explored. The distribution of these genes in large collections of strains representing the genetic diversity of bean bacterial blight pathogens and allele sequence comparison should reveal their evolutionary history and allow the selection of candidates for further functional analyses.

While Xff 4834-R is well adapted to survive in the phyllopshere and to colonize seeds notably through adhesion and biofilm aggregation $[13,14,16]$ and is highly pathogenic on bean, genome sequence analysis reveals that this strain lacks a functional flagellum. Isolation of such variants from a natural epidemic reveals that either 
flagellar motility is not a key function for in planta fitness or that some complementation occurs within the bacterial population. Mixing of flagellated and non-flagellated cells in population could also be a strategy to avoid detection by plant defense system by reducing the targets.

Finally, the sequencing and annotation of Xff 4834-R genome allowed the discovery of the genetic basis of the fuscous pigment production, a characteristic of all Xff strains. Fuscous variants belonging to separate pathovars within Xanthomonas are sometimes isolated. It will be interesting to test if the same genetic basis is responsible for these phenotypes that did not fixed in these populations. It shall now be feasible to replace $\psi h m g A$ by a functional ortholog to identify the role of this pigment in Xff fitness.

\section{Methods}

\section{Bacterial strain}

Xff 4834- $\mathrm{R}$ is a spontaneous rifamycin resistant derivative of Xff CFBP4834, which was isolated from an epiphytic biofilm from an asymptomatic bean leaflet (cv. Michelet) sampled in a highly infected bean field in Beaucouzé, France, in 1998. Sequenced strain 4834-R is referred to as CFBP 4885 in the French Collection of Plant Pathogenic Bacteria (http://www.angers.inra.fr/ $\mathrm{cfbp} /$ ). This strain is highly aggressive on bean (data not shown) and well adapted to bean phyllosphere [13].

\section{Genome sequencing, assembly and finishing}

To perform the complete sequence of Xff 4834-R, a mix of capillary Sanger and next-generation sequencing was used. Around 20X coverage of 454 GS-FLX (Roche, www.roche.com) reads were added to Sanger reads, which was derived from a $10 \mathrm{~kb}$ insert fragment size library. This library was constructed after mechanical shearing of genomic DNA and cloning of generated inserts into plasmid pCNS (pSU18-derived). Plasmid DNAs were purified and end-sequenced (26,522 reads) by dye-terminator chemistry with ABI3730 sequencers (Applied Biosystems, Foster City, USA) leading to an approximately 4-fold coverage. The reads were assembled by Newbler (Roche) and validated via the Consed interface (www.phrap.org). For the finishing phases, we used primer walking of clones, PCRs and in vitro transposition technology (Template Generation System ${ }^{\text {Ts }}$ II Kit; Finnzyme, Espoo, Finland), corresponding to 634, 66 and 2,539 additional reads, respectively. Around 76-fold coverage of Illumina reads (36 bp) were mapped, using SOAP (http://soap.genomics.org.cn), for the polishing phase as it is described by Aury et al. [157].

The sequences reported here have been deposited in the EMBL GenBank database, and accession numbers are FO681494, FO681495, FO681496, and FO681497 for the chromosome and for the three plasmids, respectively.

\section{Gene prediction and annotation}

Sequence analysis and annotation were performed using iANT (integrated ANnotation Tool; [158] as described for $X$. albilineans [34]. The probabilistic Markov model for coding regions used by the gene prediction software FrameD [159] was constructed with a set of CDS sequences obtained from the public databank Swiss-Prot as revealed by BLASTX analysis. The alternative matrices were built using genes first identified in ACURs (Alternative Codon Usage Regions) based on homology and taken from the $X$. albilineans annotation process [34]. The corresponding products were automatically annotated using a protocol based on HAMAP scan [160], InterPro domain annotation and BLASTp analysis. Predicted CDSs were manually annotated individually gene by gene by an international consortium of scientists with expertise on different gene functions on xanthomonads (http://www.reseau-xantho.org/reseau_xantho/). Start codon assignment was verified with special care and suggested automatic annotations were individually expertized to generate the proposed annotations. Proteins were classified according to MultiFun classification [161]. The complete annotated genetic map, search tools (SRS, BLAST), annotation, and process classification are available at http://iant.toulouse.inra.fr/.

\section{Genomic comparisons}

In order to perform comparative genomics with Xff 4834-R, 12 complete Xanthomonas genomes publicly available at the time of this analysis were selected (Table 2). Identification of orthologous groups between genomes was achieved by orthoMCL analyses [162] with the 15 genomes, including two closely related genera (Table 2). OrthoMCL clustering analyses were performed using the following parameters: P-value Cut-off $=1 \times 10^{-5}$; Percent Identity Cut-off $=0$; Percent Match Cut-off $=80$; MCL Inflation $=1.5$; Maximum Weight $=316$. We modified OrthoMCL analysis by inactivating the filter query sequence during the BLASTP pre-process. From results are defined unique CDSs, corresponding to CDSs present only in one copy in one genome, and groups of orthologs that correspond to CDSs present in one copy in at least two genomes. The main part of comparative analyses of genomes and figures are deduced from their distribution. Furthermore, genomes contain CDSs that are present at least in two copies (paralogs) in one or more genomes. The abundance of this kind of CDSs is variable in Xanthomonas genomes, from $22.1 \%$ of the CDSs in Xoo PXO99A to $3.61 \%$ in $\mathrm{Xcr} 756 \mathrm{C}$, Xff 4834-R having 4.75\%. Distribution of this kind of CDSs with paralogs is also indicated on figures and, when possible, the number of paralogs is related to the corresponding genome. Groups of homologs refer to groups of orthologs having or not paralogs. 
Chromosomal rearrangements were explored using the progressive MAUVE algorithm as implemented in Mauve v2.3.1 [163].

\section{Phylogeny of organisms used for genomic comparison} The complete nucleotide sequences of a set of six housekeeping genes ( $a t p D, d n a K$, efP, $g \ln A, \operatorname{gyr} B, r p o D)$ were extracted from the 15 genomes (Table 2). Whole amino acid sequences were aligned using ClustalW with a BLOSUM protein weight matrix and transposed back to nucleotide sequence level to gain a codon-based alignment. The alignments were manually edited with Bioedit Sequence Alignment Editor Software 7.0.9.0 [164]. Sequences were concatenated following the alphabetic order of the genes using Geneious 4.8.4. A phylogenetic tree was constructed using the Maximum Likelihood method (ML). The model of evolution for the ML analysis was determined using ModelTest 3.7 in Paup. Both hierarchical likelihood ratio test (hLRT) and the standard Akaike Information criterion (AICc) were used to evaluate the model scores. Phylogenetic tree and bootstraps values were obtained using PhyML 3.0 [165]. Bootstraps analyses were done with 1000 iterations. Trees were visualized and finalized with Mega 5.03 [166].

\section{Pseudogenization study}

Different kind of events are considered in this study: gene fragmentation detected by genomic comparison, insertion or deletion resulting in frameshift in coding regions modifying the length or the sequence of the predicted peptide, mutations resulting in an early stop codon, and insertion of IS. Degenerated transposase or phage genes are not taken into account in this study. Differences in the Nterminal part of the predicted protein ( $\mathrm{N}$-terminal truncated predicted peptides) are also not considered as prediction of start codons still remains to be confirmed by RNA sequencing. Frameshifts are detected with FrameD [159]. Frameshifts in the following CDSs have been confirmed by Sanger sequencing: XFF4834R_chr09400 (glucuronoxylanase), XFF4834R_chr36560 (methyl-accepting chemotaxis protein), XFF4834R_chr32500 (endo-1, 3-beta-glucanase), XFF4834R_chr32600 (xylosidase), XFF4834R_chr41020 (alpha-glucuronidase), XFF4834R_chr26090 (GumN), XFF 4834R_chr19550 (adhesin-like hemagglutinin), XFF4834R_ chr34200 (XagA), XFF4834R_chr12700 (PilQ), XFF4834R_ chr36560 (methyl-accepting chemotaxis protein) and XFF4834R_chr41250 (endo-1,4-beta-xylanase). Primers were selected upstream and downstream of the frameshift in order to amplify a unique sequence in Xff 4834-R genome. Primers were validated by blast on Xff 4834-R genome with parameters for short queries with a minimum number of nucleotide matches of $15 \mathrm{nt}$ and a maximum number of 5 mismatches. Primers were then checked in silico for specific and efficient gene amplifications (Amplify software version 3.1.4). Primer description is available in Additional file 9. PCRs were performed as previously described [17] and amplicons were sequenced using Sanger technology (Genoscreen, France). Presence of CDSs that are putative pseudogenes in Xff 4834-R genome was assessed in the 15 genomes used in genomic comparisons by BLAST of the nucleic sequences (Additional file 3). When available, nucleic sequences of the corresponding genes were used to build a Neighbor-joining $(\mathrm{Nj})$ tree using Phylip 3.69 that is further drawn with Njplot 2.3. Topology of each tree was compared with the phylogeny of the organisms as represented by the ML tree with the six housekeeping genes (see above). When pseudogene phylogeny was not congruent with the phylogeny of the organisms, genomic context of the pseudogene was analyzed further to get insight into the kind of event involved in the pseudogenization.

\section{Design of PCR tests for analysis of flagellar cluster diversity} Consensus primer pairs were designed based on aligned flagellar clusters of Xfa ICPB 10535, Xac 306, Xa pv. manihotis CIO151, Xcv 85-10, Xv ATCC 35937, X. campestris pv. vasculorum NCPPB702, Xcm NCPPB4381, Xcc ATCC 33913, Xoc BLS256, Xoo KACC10331, and Xal GPE PC73). These primers aimed at amplifying seven genes, $f l i M, f l i E$, fleQ, fliC, flgE, flgB, and $f l g A$, chosen as markers of the flagellar cluster integrity in a collection of more than 300 Xanthomonas strains. The list of these strains and their characteristics is available upon request. PCR assays were performed in $20-\mu \mathrm{l}$ volumes containing $200 \mu \mathrm{M}$ dNTP, $0.125 \mu \mathrm{M}$ each primer (Additional file 6), $4 \mu \mathrm{l}$ of GoTaq $5 \mathrm{X}$ buffer, $0.4 \mathrm{U} / \mu \mathrm{l}$ of GoTaq polymerase, and $5 \mu \mathrm{l}$ of a boiled bacterial suspension $\left(1 \times 10^{7} \mathrm{CFU} / \mathrm{ml}\right)$. PCR conditions were $3 \mathrm{~min}$ at $94^{\circ} \mathrm{C}$; followed by 35 cycles of $30 \mathrm{~s}$ at $94^{\circ} \mathrm{C}, 30 \mathrm{~s}$ at annealing temperature specific of each primer pair, an elongation time adapted to amplicon size at $72^{\circ} \mathrm{C}$; and ended with $10 \mathrm{~min}$ at $72^{\circ} \mathrm{C}$. PCR amplifications were performed in duplicate for each strain.

\section{Motility tests}

Strain motility was tested in soft-agar assays. Xanthomonad strains were grown at $28^{\circ} \mathrm{C}$ up to 12 days in MOKA (yeast extract $4 \mathrm{~g} / \mathrm{l}$; casamino acids $8 \mathrm{~g} / \mathrm{l} ; \mathrm{KH}_{2} \mathrm{PO}_{4} 2 \mathrm{~g} / \mathrm{l}$; $\mathrm{MgSO}_{4} .7 \mathrm{H}_{2} \mathrm{O} 0.3 \mathrm{~g} / \mathrm{l}$ ) medium containing $0.2 \%$ agar and $0.05 \%$ tetrazolium chloride. A drop $(10 \mu \mathrm{l})$ of a $1 \mathrm{x}$ $10^{8} \mathrm{cfu} / \mathrm{ml}$ suspension is deposited in the middle of the plate and the radius of the colony measured every two days and imaged at five days.

\section{Additional files}

Additional file 1: Distribution of CDSs exclusively shared by Xanthomonas fuscans subsp. fuscans strain 4834-R (Xff 4834-R) and only one of the 15 strains used in comparative genomics. The strains, 
Xff 4834-R, X. fuscans subsp. aurantifolii strain ICPB10535 (Xfa ICPB10535), $X$. citri pv. citri strain 306 (Xac 306), X. axonopodis subsp. citrumelonis strain F1 (Xacm F1), X. euvesicatoria strain 85-10 (Xcv 85-10), X. campestris pv. musacearum strain NCPPB4381 (XCm NCPPB4381), X. oryzae pv. oryzae strain PXO99A (Xoo PXO99A), X. oryzae pv. oryzicola strain BLS256 (XoC BLS256), X. gardneri strain ATCC19865 (Xg ATCC19865), X. vesicatoria strain ATCC35937 (XV ATCC35937), X. campestris pv. campestris strain ATCC33913 (XCC ATCC33913), X. campestris pv. raphani strain $756 C$ (Xcr 756C), Xylella fastidiosa strain Temecula1 (Xf Temecula1), Stenotrophomonas maltophilia strain R551-3 (Sm R551-3), and X. albilineans strain GPE PC73 (Xal GPE PC73), are organized according to their phylogeny represented by the Maximum Likelihood phylogenetic tree based on six housekeeping gene sequences ( $a t p D$, dnaK, efP, $g \ln A, g y r B, r p o D)$. Bold line indicates that bootstrap value (1000 replicates) is 100, if not, bootstrap value of the branch is indicated on the tree. Branch length for Xf Temecula1 is 0.6 substitution per site.

Additional file 2: List of the 240 unique CDSs of Xff 4834-R genome based on comparisons with the genomes of 12 other Xanthomonas spp. and two closely related organisms.

Additional file 3: List of putative pseudogenes and gene fragments in the genome of Xff 4834R.

Additional file 4: Occurrences of PIP box motifs in the genome of Xff 4834R.

Additional file 5: Insertion of extrachromosomal elements in Xff 4834R genome and related enzymes.

Additional file 6: Primers for amplification of selected flagellum genes.

Additional file 7: Comparative maps of the integron regions in Xcc ATCC33913 and Xff 4834-R. Are represented the integrase gene fragment intl (blue cassette), the integron-associated recombination site (attl, shown as a diamond), the pigH gene fragment (yellow cassette), several hypothetical protein encoding genes (grey cassettes), 59-base elements (be) (small square) and several insertion sequences (red cassettes). The attl and 59-be sites are white filled if their recombination site does not conform to the consensus sequence 5-GTTRRRY. Colored cassettes indicate orthologs.

Additional file 8: Examples of phylogenetic trees (Neighbor-joining) obtained for gene families having a putative pseudogene in Xff 4834-R: (a) XFF4834R_chr05500 is a frameshifted gene for which two overlapping peptides could be predicted and phylogenetic tree has a topology similar to that of housekeeping genes, (b) XFF4834R_25070-25100 is disrupted by ISXax1 insertion (c) XFF4834R_chr25180 is a degenerated fragment of pigH, probably related to an integron insertion acquired from $X c c$ and (d) XFF4834R_chr33800 is a frameshifted gene for which two peptides could still be predicted.

Additional file 9: Primers for verification of frameshifts of selected CDSs.

\section{Abbreviations}

ACUR: Alternative codon usage region; CDS: Protein-coding sequence; Hrp: Hypersensitive response and pathogenicity; IS: Insertion sequence; MLSA: Multilocus sequence analysis; rpf: Regulation of pathogenicity factors; T1SS to T6SS: Type I to Type VI secretion systems; T3SP: Type III secreted proteins; T3Es: Type III effectors; TCRS: Two component regulatory system; CWDE: Cell wall-degrading enzyme; TBDT: TonB-dependant transporter.

\section{Competing interests}

The authors declare that they have no competing interests.

\section{Authors' contributions}

$\mathrm{AD}$ contributed to manual annotation of the genome and analysis of the data, and drafted parts of the manuscript. SC (Carrère) performed automatic annotation of the genome and OrthoMCL analysis. VB and SF performed sequencing of the genome. TB contributed to manual annotation of the genome and analysis of the data, and drafted part of the manuscript. RK contributed to manual annotation of the genome and analysis of the data. MLAO, SB, CB, SC (Cociancich), KD, LG, FG, EL, AM, LDN, EG, IP, SP, OP, IRS,
$\mathrm{PR}, \mathrm{MR}, \mathrm{BS}, \mathrm{MAVS}, \mathrm{W}, \mathrm{CV}$ and MA contributed to manual annotation of the genome and revised the manuscript. Al performed the flagellum distribution study. LSG performed OrthoMCL analysis and contributed to pseudogene analysis. CM conceived the study and revised the manuscript. MAJ conceived the study, contributed to manual annotation of the genome and analysis of the data, drafted parts of the manuscript, and coordinated the annotation project. All authors read and approved the final manuscript.

\section{Acknowledgements}

Al is funded by a PhD grant from INRA-SPE and region Pays de la Loire, France. EG was funded by a PhD grant from the French Ministry of National Education and Research and French Guyana. SC, EG, MA, EL and LDN are funded by the LABEX TULIP (ANR-10-LABX-41), LSG is funded by ANR-2010GENM-013 Xanthomix.

\section{Author details}

'INRA, UMR1345 Institut de Recherche en Horticulture et Semences, F-49071, Beaucouzé, France. ${ }^{2}$ AGROCAMPUS OUEST, UMR1345 Institut de Recherche en Horticulture et Semences, F-49045, Angers, France. ${ }^{3}$ Université d'Angers, UMR1345 Institut de Recherche en Horticulture et Semences, SFR 4207 QUASAV, PRES L'UNAM, F-49045, Angers, France. ${ }^{4}$ INRA, LIPM UMR 441, F-31326, Castanet-Tolosan, France. ${ }^{5}$ CNRS, LIPM UMR 2594, F-31326, Castanet-Tolosan, France. ${ }^{6} \mathrm{CEA}$, Genoscope, Centre National de Séquençage, F-91057, Evry Cedex, France. ${ }^{7}$ Universidad de Los Andes, Laboratorio de Micología y Fitopatología Uniandes, Bogotá, Colombia. ${ }^{8} \mathrm{CIRAD}$, UMR BGPI, F-34398, Montpellier Cedex 5, France. ${ }^{9}$ CIRAD, UMR PVBMT, F-97410, Saint-Pierre, La Réunion, France. ${ }^{10}$ Université de la Réunion, UMR PVBMT, F-97715, Saint-Denis, La Réunion, France. ${ }^{11}$ IRD, UMR RPB, F-34394, Montpellier Cedex 5, France. ${ }^{12}$ GaTE Lab Botanica IBUSP 277 05508-900, São Paulo, SP, Brasil. ${ }^{13}$ Université de Toulouse, Université Paul Sabatier, UMR LIPM, F-31326, Castanet-Tolosan Cedex, France. ${ }^{14}$ Current address: Department of Biology, Center for Genomics and Systems Biology, New York University, 10003, New York, NY, USA. ${ }^{15}$ Current address: ANSES, Laboratoire de Santé des végétaux, F-49044, Angers, France.

Received: 18 July 2013 Accepted: 26 October 2013 Published: 6 November 2013

\section{References}

1. Hayward AC: The hosts of Xanthomonas. In Xanthomonas. Edited by Swings JG, Civerolo EL. London, United Kingdom: Chapman \& Hall; 1993:1-119.

2. Vauterin L, Rademaker J, Swings J: Synopsis on the taxonomy of the genus Xanthomonas. Phytopathology 2000, 90:677-682.

3. Vauterin L, Hoste B, Kersters K, Swings J: Reclassification of Xanthomonas. Int J Syst Bacteriol 1995, 45:472-489.

4. Dye DW, Bradbury JF, Goto M, Hayward AC, Lelliott RA, Schroth MN International standards for naming pathovars of phytopathogenic and a list of pathovar names and pathotype strains. Rev Plant Pathol 1980, 59:153-168.

5. Broughton WJ, Hern G, Blair M, Beebe S, Gepts P, Vanderleyden J: Beans (Phaseolus spp.) - model food legumes. Plant Soil 2003, 252:55-128.

6. Vidaver AK: Xanthomonas campestris pv. phaseoli: cause of common bacterial blight of bean. In Xanthomonas. Edited by Swings JG, Civerolo EL. London, United Kingdom: Chapman \& Hall; 1993:40-44.

7. Graham PH, Vance CP: Update on legume utilization legumes: importance and constraints to greater Use. Plant Physiol 2003, 131:872-877.

8. Kaplan L, Lynch TF: Phaseolus ( fabaceae ) in archaeology: AMS. Econ Bot 1999, 53:261-272.

9. Gepts P: Origin and evolution of common bean: past events and recent trends. Hortscience 1998, 33:1124-1130.

10. Singh SP, Munoz CG: Resistance to common bacterial blight among phaseolus species and common bean improvement. Crop Sci 1999, 39:80-89.

11. Miklas PN, Kelly JD, Beebe SE, Blair MW: Common bean breeding for resistance against biotic and abiotic stresses: from classical to MAS breeding. Euphytica 2006, 147:105-131.

12. Weller DM, Saettler AW: Colonization and distribution of Xanthomonas phaseoli and Xanthomonas phaseoli var. fuscans in field-grown navy beans. Phytopathology 1980, 70:500-506.

13. Jacques M, Josi K, Darrasse A, Samson R: Xanthomonas axonopodis pv. Phaseoli var. Fuscans Is aggregated in stable Biofilm population sizes in the phyllosphere of Field-grown beans. Appl Environ Microbiol 2005, 71:2008-2015. 
14. Darrasse A, Bureau C, Samson R, Morris C, Jacques M-A: Contamination of bean seeds by Xanthomonas axonopodis pv. phaseoli associated with low bacterial densities in the phyllosphere under field and greenhouse conditions. Eur J Plant Pathol 2007, 119:203-215.

15. Büttner D, Bonas U: Regulation and secretion of Xanthomonas virulence factors. FEMS Microbiol Rev 2010, 34:107-133.

16. Darsonval A, Darrasse A, Durand K, Bureau C, Cesbron S, Jacques M-A: Adhesion and fitness in the bean phyllosphere and transmission to seed of Xanthomonas fuscans subsp. fuscans. Mol Plant Microbe Interact 2009, 22:747-757.

17. Darsonval A, Darrasse A, Meyer D, Demarty M, Durand K, Bureau C, Manceau C, Jacques M-A: Type III secretion system of Xanthomonas fuscans subsp. fuscans is involved in the phyllosphere colonization process and in transmission to seeds of susceptible beans. Appl Environ Microbiol 2008, 74:2669-2678.

18. Hajri A, Brin C, Hunault G, Lardeux F, Lemaire C, Manceau C, Boureau T, Poussier S: $A$ « repertoire for repertoire » hypothesis : repertoires of type three effectors are candidate determinants of host specificity in xanthomonas. PLoS One 2009, 4(8):E6632.

19. Goodwin PH, Sopher CR: Water stress in leaves of Phaseolus vulgaris infected with Xanthomonas campestris pv. phaseoli. J Phytopathol 1994, 140:219-226.

20. Birch PRJ, Hyman LJ, Taylor R, Opio AF, Bragard C, Toth IK: RAPD PCR-based differentiation of Xanthomonas campestris pv. phaseoli and Xanthomonas campestris pv. phaseoli var. fuscans. Eur J Plant Pathol 1997, 103:809-814.

21. Toth IK, Hyman LJ, Taylor R, Birch PRJ: PCR-based detection of Xanthomonas campestris pv. phaseoli var. fuscans in plant material and its differentiation from X. c. pv. phaseoli. J App/ Microbiol 1998, 85:327-336.

22. Fourie D: Distribution and severity of bacterial diseases on Dry beans (phaseolus vulgaris L.) in south africa. J Phytopathol 2002, 150:220-226.

23. Gilbertson RI, Otoya MM, Pastor-Corrales MA, Maxwell DP: Genetic diversity in common blight bacteria is revealed by cloned repetitive DNA sequences. Annual Report of the Bean Improvement Cooperative 1991, 34:37-38.

24. Mkandawire ABC, Mabagala RB, Guzman P, Gepts P, Gilbertson RL: Genetic diversity and pathogenic variation of common blight bacteria (Xanthomonas campestris pv. phaseoli and X. campestris pv. phaseoli var. fuscans) suggests pathogen coevolution with the common bean. Phytopathology 2004, 94:593-603.

25. Alavi SM, Sanjari S, Durand F, Brin C, Manceau C, Poussier S: Assessment of the genetic diversity of Xanthomonas axonopodis pv. phaseoli and Xanthomonas fuscans subsp. fuscans as a basis to identify putative pathogenicity genes and a type III secretion system of the SPI-1 family by multiple suppression subtractive hybridizations. App/ Environ Microbio/ 2008, 74:3295-3301

26. Mhedbi-hajri N, Hajri A, Boureau T, Darrasse A, Durand K, Brin C, Fischer-Le Saux M, Manceau C, Poussier S, Pruvost O, et al: Evolutionary history of the plant pathogenic bacterium xanthomonas axonopodis. PLoS One 2013, 8:e58474.

27. Rademaker JLW, Louws FJ, Schultz MH, Rossbach U, Vauterin L, Swings J, de Bruijn FJ: A comprehensive species to strain taxonomic framework for Xanthomonas. Phytopathology 2005, 95:1098-1111.

28. Bull CT, de Boer SH, Denny TP, Firrao G, Fischer-Le Sau M, Saddler G, Scortichini M, Stead DE, Takikawa Y: List of New names of plant pathogenic bacteria (2008-2010). J Plant Pathol 2012, 94:21-27.

29. Burkholder $\mathrm{WH}$ : The bacterial diseases of bean: a comparative study. In 1930; Ithaca. N. Y: Agric. Exp. Stn; 1930:88.

30. Ryan RP, Vorhölter F-j, Potnis N, Jones JB, van Sluys M-A, Bogdanove AJ, Dow JM: Pathogenomics of Xanthomonas: understanding bacterium plant interactions. Nat Rev Microbiol 2011, 9:344-355.

31. Chinchilla D, Bauer Z, Regenass M, Boller T, Felix G: The arabidopsis receptor kinase FLS2 binds flg22 and determines the specificity of flagellin perception. Plant Cell 2006, 18:465-476.

32. Oblessuc PR, Borges A, Chowdhury B, Caldas DGG, Tsai SM, Camargo LEA, Melotto M: Dissecting Phaseolus vulgaris innate immune system against Colletotrichum lindemuthianum infection. PLoS One 2012, 7:e43161.

33. Saddler GS, Bradbury JF: Family I . Xanthomonadaceae fam. nov. In Bergey's Manual of Systematic Bacteriology 2nd ed Vol 2 (The Proteobacteria), Part B (The Gammaproteobacteria). 2nd edition. Edited by Springer-Verlag. Berlin, Germany: Garrity, G; 2005:63.

34. Pieretti I, Royer M, Barbe V, Carrere S, Koebnik R, Cociancich S, Couloux A, Darrasse A, Gouzy J, Jacques M-A, et al: The complete genome sequence of Xanthomonas albilineans provides new insights into the reductive genome evolution of the xylem-limited Xanthomonadaceae. BMC Genomics 2009, 10:616.
35. Riley M: Functions of the gene products of Escherichia coli. Microbiol Rev 1993, 57:862-952.

36. Tettlin H, Masignani V, Cieslewicz MJ, Donati C, Medini D, Ward NL, Angiuoli SV, Crabtree J, Jones AL, Durkin AS, et al: Genome analysis of multiple pathogenic isolates of streptococcus agalactiae: implications for the microbial " pan-genome ". Proc Natl Acad Sci U S A 2005, 102:13950-13955.

37. Zhao Y, Wu J, Yang J, Sun S, Xiao J, Yu J: PGAP : pan-genomes analysis pipeline. Bioinformatics 2012, 28:416-418.

38. Lu H, Patil P, Van Sluys M-A, White FF, Ryan RP, Dow JM, Rabinowicz P, Salzberg SL, Leach JE, Sonti R, et al: Acquisition and evolution of plant pathogenesis-associated gene clusters and candidate determinants of tissue-specificity in Xanthomonas. PloS One 2008, 3:e3828.

39. Bogdanove AJ, Koebnik R, Lu H, Furutani A, Angiuoli SV, Patil PB, Van Sluys M-A, Ryan RP, Meyer DF, Han S-W, et al: Two new complete genome sequences offer insight into host and tissue specificity of plant pathogenic Xanthomonas spp. J Bacterio/ 2011, 193:5450-5464.

40. Young JM, Park DC, Shearman H, Fargier E: A multilocus sequence analysis of the genus Xanthomonas. Syst Appl Microbiol 2008, 31:366-377.

41. Jalan N, Aritua V, Kumar D, Yu F, Jones JB, Graham JH, Setubal JC, Wang N: Comparative genomic analysis of xanthomonas axonopodis pv. Citrumelo F1, which causes citrus bacterial spot disease, and related strains provides insights into virulence and host specificity. J Bacteriol 2011, 193(22):6342-6357.

42. da Silva ACR, Ferro JA, Reinach FC, Farah CS, Furlan LR, Quaggio RB, Monteiro-Vitorello CB, Van Sluys MA, Almeida NF, Alves LMC, et al: Comparison of the genomes of two Xanthomonas pathogens with differing host specificities. Nature 2002, 417:459-463.

43. Studholme D, Kemen E, MacLean D, Schornack S, Aritua V, Thwaites R, Grant M, Smith J, Jones JD: Genome-wide sequencing data reveals virulence factors implicated in banana Xanthomonas wilt. FEMS Microbiol Lett 2010, 310(2):182-192.

44. Thieme F, Koebnik R, Bekel T, Berger C, Boch J, Büttner D, Caldana C, Gaigalat L, Goesmann A, Kay S, et al: Insights into genome plasticity and pathogenicity of the plant pathogenic bacterium Xanthomonas campestris pv. vesicatoria revealed by the complete genome sequence. J Bacteriol 2005, 187(21):7254-7266.

45. Moreira LM, Almeida NF, Potnis N, Diqanpietri LA, Adi SS, Bortolossi JC, da Silva AM, de Moraes AM, de Oliveira JC, de Souza RF, et al: Novel insights into the genomic basis of citrus canker based on the genome sequences of two strains of Xanthomonas fuscans subsp. aurantifolii. BMC Genomics 2010, 11:238.

46. Potnis N, Krasileva K, Chow V, Almeida NF, Patil PB, Ryan RP, Sharlach M, Behlau F, Dow JM, Momol MT, et al: Comparative genomics reveals diversity among xanthomonads infecting tomato and pepper. BMC Genomics 2011, 12:146.

47. Salzberg SL, Sommer DD, Schatz MC, Phillippy AM, Rabinowicz PD, Tsuge S, Furutani A, Ochiai H, Delcher AL, Kelley D, et al: Genome sequence and rapid evolution of the rice pathogen Xanthomonas oryzae pv. oryzae PX099A. BMC Genomics 2008, 9:204.

48. Van Sluys MA, de Oliveira MC, Monteiro-Vitorello CB, Miyaki CY, Furlan LR, Camargo LE, da Silva AC, Moon DH, Takita MA, Lemos EG, et al: Comparative analyses of the complete genome sequences of Pierce's disease and citrus variegated chlorosis strains of Xylella fastidiosa. J Bacteriol 2003, 185(3):1018-1026.

49. Lukjancenko O, Ussery DW, Wassenaar TM: Comparative genomics of bifidobacterium, lactobacillus and related probiotic genera. Microb Ecol 2012, 63:651-673.

50. Bannantine J, Wu C-W, Hsu C, Zhou S, Schwartz DC, Bayles DO, Paustian ML, Alt DP, Sreevatsan S, Kapur V, et al: Genome sequencing of ovine isolates of Mycobacterium avium subspecies paratuberculosis offers insights into host association. BMC Genomics 2012, 13:89.

51. Baltrus D, Nishimura MT, Romanchuk A, Chang JH, Mukhtar MS, Cherkis K, Roach J, Grant SR, Jones CD, Dangl JL: Dynamic evolution of pathogenicity revealed by sequencing and comparative genomics of 19 Pseudomonas syringae isolates. PLoS Pathog 2011, 7:e1002132.

52. Meyer D, Bogdanove AJ: Genomics-driven advances in Xanthomonas biology. In Plant Pathogenic Bacteria: Genomics and Molecular Biology. Edited by Jackson R. Norfolk: Caister Academic Press; 2009:147-161.

53. Guieysse B, Wuertz S: Metabolically versatile large-genome prokaryotes. Curr Opin Biotechnol 2011, 23:1-7

54. Beattie GA, Lindow SE: The secret life of foliar bacterial pathogens on leaves. Annu Rev Phytopathol 1995, 33:145-172. 
55. Pieretti I, Royer M, Barbe V, Carrere S, Koebnik R, Couloux A, Darrasse A, Gouzy J, Jacques M-A, Lauber $E$, et al: Genomic insights into strategies used by Xanthomonas albilineans with its reduced artillery to spread within sugarcane xylem vessels. BMC Genomics 2012, 13:658.

56. Galperin MY: Bacterial signal transduction network in a genomic perspective. Environ Microbiol 2004, 6:552-567.

57. Galperin MY: A census of membrane-bound and intracellular signal transduction proteins in bacteria: Bacterial IQ, extroverts and introverts. BMC Microbiol 2005, 5:35.

58. Qian W, Han Z-J, He C: Two-component signal transduction systems of xanthomonas spp.: a lesson from genomics. Mol Plante-Microbe Interact 2008, 21:151-161.

59. Galperin MY, Koonin EV: From complete genome sequence to 'complete ' understanding ? Trends Biotechnol 2010, 28:398-406.

60. Kim D-J, Forst S: Genomic analysis of the histidine kinase family in bacteria and archaea. Microbiology 2001, 147:1197-1212.

61. Craig L, Li J: Type IV pili: paradoxes in form and function. Curr Opin StruC Biol 2008, 18:267-277.

62. Burrows LL: Pseudomonas aeruginosa twitching motility: type IV pili in action. Annu Rev Microbiol 2012, 66:493-520.

63. Korotkov KV, Sandkvist M, Hol WGJ: The type II secretion system: biogenesis, molecular architecture and mechanism. Nat Rev Microbiol 2012, 10:336-351.

64. Meng Y, Li Y, Galvani CD, Hao G, Turner JN, Burr TJ, Hoch HC: Upstream migration of Xylella fastidiosa via pilus-driven twitching motility. J Bacteriol 2005, 187:5560-5567.

65. Lim SM, So B-H, Wang J, Song ES, Park Y-J, Lee B-M, Kang H-W: Functional analysis of pilQ gene in Xanthomanas oryzae pv. oryzae, bacterial blight pathogen of rice. J Microbiol 2008, 46:214-220.

66. Waksman G, Hultgren SJ: Structural biology of the chaperone-usher pathway of pilus biogenesis. Nat Rev Micro 2009, 7:765-774

67. Desvaux M, Hébraud M, Talon R, Henderson IR: Outer membrane translocation: numerical protein secretion nomenclature in question in mycobacteria. Trends Microbiol 2009, 17:338-340.

68. Dautin N, Bernstein HD: Protein secretion in gram-negative bacteria via the autotransporter pathway. Annu Rev Microbiol 2007, 61:89-112.

69. Cotter SE, Surana NK, St Geme JW: Trimeric autotransporters: a distinct subfamily of autotransporter proteins. Trends Microbiol 2005, 13:199-205.

70. Linke D, Riess T, Autenrieth IB, Lupas A, Kempf VAJ: Trimeric autotransporter adhesins: variable structure, common function. Trends Microbiol 2006, 14:264-270

71. Mazar J, Cotter PA: Topology and maturation of filamentous haemagglutinin suggest a new model for two-partner secretion. $\mathrm{Mol}$ Microbiol 2006, 62:641-654

72. Mhedbi-Hajri N, Darrasse A, Pigné S, Durand K, Fouteau S, Barbe V, Manceau C, Lemaire $C$, Jacques M-A: Sensing and adhesion are adaptive functions in the plant pathogenic xanthomonads. BMC Evol Biol 2011, 11:67.

73. Sutherland IW: Xanthan. In Xanthomonas. Edited by Swings J-G, Civerolo EL. London: Chapman \& hall; 1993:363-388.

74. García-Ochoa F, Santos VE, Casas JA, Gómez E: Xanthan gum: production, recovery, and properties. Biotechnol Adv 2000, 18:549-579.

75. Vu B, Russel JC, Ivanova EP: Bacterial extracellular polysaccharides involved in biofilm formation. Molecules 2009, 14:2535-2554.

76. El-Banoby FE, Rudolph KWE: Multiplication of Xanthomonas campestris pvs secalis and translucens in host and non-host plants (rye and barley) and development of water soaking. EPPO Bull 1989, 19:105-111.

77. Vidhyasekaran P, Alvenda ME, Mew TW: Physiological changes in rice seedlings induced by extracellular polysaccharide produced by Xanthomonas campestris pv. oryzae. Physiol Mol Plant Pathol 1989, 35:391-402.

78. Dunger G, Relling VM, Tondo ML, Barreras M, lelpi L, Orellano EG, Ottado J: Xanthan is not essential for pathogenicity in citrus canker but contributes to Xanthomonas epiphytic survival. Arch Microbiol 2007, 188:127-135.

79. Rigano LA, Siciliano F, Enrique R, Sendín L, Filippone P, Torres PS, Qüesta J, Dow JM, Castagnaro AP, Vojnov AA, et al: Biofilm formation, epiphytic fitness, and canker development in xanthomonas axonopodis pv. Citri. Mol Plant Microbe Interact 2007, 20:1222-1230.

80. Vorhölter F-J, Schneiker S, Goesmann A, Krause L, Bekel T, Kaiser O, Linke B, Patschkowski T, Rückert C, Schmid J, et al: The genome of Xanthomonas campestris pv. campestris B100 and its use for the reconstruction of metabolic pathways involved in xanthan biosynthesis. J Biotech 2008, 134:33-45.
81. Yoon $\mathrm{K}-\mathrm{H}, \mathrm{Cho} \mathrm{J}-\mathrm{Y}$ : Transcriptional analysis of the gum gene cluster from Xanthomonas oryzae pathovar oryzae. Biotechnol Lett 2007, 29:95-103.

82. Köplin R, Arnold W, Hotte B, Simon R, Wang GE, Puhler A: Genetics of xanthan production in xanthomonas campestris: the xanA and xan $B$ genes Are involved in UDP-glucose and GDP-mannose biosynthesis. J Bacteriol 1992, 174:191-199.

83. Tao F, Swarup S, L-h Z, Biology C: Quorum sensing modulation of a putative glycosyltransferase gene cluster essential for Xanthomonas campestris biofilm formation. Environ Microbiol 2010, 12:3159-3170.

84. Wang $X$, lii JFP, Romeo T: The pgaABCD locus of escherichia coli promotes the synthesis of a polysaccharide adhesin required for biofilm formation. J Appl Microbiol 2004, 186:2724-2734.

85. Bobrov AG, Kirillina O, Forman S, Mack D, Perry RD: Insights into Yersinia pestis biofilm development: topology and co-interaction of Hms inner membrane proteins involved in exopolysaccharide production. Environ Microbiol 2008, 10:1419-1432

86. Raetz CRH, Whitfield C: Lipopolysaccharide endotoxins. Annu Rev Biochem 2002, 71:635-700.

87. Sperandeo $P$, Dehò G, Polissi A: The lipopolysaccharide transport system of gram-negative bacteria. Biochim Biophys Acta 2009, 1791:594-602.

88. Steinmann D, Köplin R, Pühler A, Niehaus K: Xanthomonas campestris pv. Campestris Ips/ and IpsJ genes encoding putative proteins with sequence similarity to the $a$ - and -subunits of 3-oxoacid CoA-transferases are involved in LPS biosynthesis. Arch Microbiol 1997, 168:441-447.

89. Raetz CRH, Reynolds CM, Trent MS, Bishop RE: Lipid a modification systems in gram-negative bacteria. Annu Rev Biochem 2007, 76:295-329.

90. Patil PB, Bogdanove AJ, Sonti RV: The role of horizontal transfer in the evolution of a highly variable lipopolysaccharide biosynthesis locus in xanthomonads that infect rice, citrus and crucifers. BMC Evol Biol 2007, 7:243.

91. Perepelov AV, Li D, Liu B, Senchenkova SN, Guo D, Shevelev SD, Shashkov AS, Guo X, Feng L, Knirel YA, et al: Structural and genetic characterization of 099 antigen. FEMS Immunol Med Microbiol 2009, 57:80-87.

92. Neugebauer H, Herrmann C, Kammer W, Schwarz G, Nordheim A, Braun V: ExbBD-dependent transport of maltodextrins through the novel MalA protein across the outer membrane of caulobacter crescentus. J Bacteriol 2005, 187:8300-8311.

93. Blanvillain S, Meyer D, Boulanger A, Lautier M, Guynet C, Denancé N, Vasse J, Lauber E, Arlat M: Plant carbohydrate scavenging through TonBdependent receptors: a feature shared by phytopathogenic and aquatic bacteria. PLoS One 2007, 2(2):e224.

94. Eisenbeis S, Lohmiller S, Valdebenito M, Leicht S, Braun V: NagA-dependent uptake of $\mathrm{N}$-acetyl-glucosamine and $\mathrm{N}$-acetyl-chitin oligosaccharides across the outer membrane of caulobacter crescentus. J Bacteriol 2008, 190:5230-5238.

95. Schauer K, Rodionov D, de Reuse H: New substrates for TonB-dependent transport: do we only see the 'tip of the iceberg'? Trends Biochem Sci 2008, 33:330-338.

96. Noinaj N, Guillier M, Barnard TJ, Buchanan SK: TonB-dependent transporters: regulation, structure, and function. Annu Rev Microbiol 2010, 64:43-60.

97. Boulanger A, Déjean G, Lautier M, Glories M, Zischek C, Arlat M, Lauber E: Identification and regulation of the $\mathrm{N}$-acetylglucosamine utilization pathway of the plant pathogenic bacterium xanthomonas campestris pv. Campestris. J Bacteriol 2010, 192:1487-1497.

98. Déjean G, Blanvillain-Baufumé S, Boulanger A, Darrasse A, de Bernonville TD, Girard A-L, Carrére S, Jamet S, Zischek C, Lautier M, et al: he xylan utilization system of the plant pathogen xanthomonas campestris pv campestris controls epiphytic life and reveals common features with oligotrophic bacteria and animal gut symbionts. New Phytol 2013.

99. Ryan RP, Dow JM: Intermolecular interactions between HD-GYP and GGDEF domain proteins mediate virulence-related signal transduction in Xanthomonas campestris. Virulence 2010, 1:404-408.

100. Gudesblat GE, Torres PS, Vojnov AA: Xanthomonas campestris overcomes Arabidopsis stomatal innate immunity through a DSF cell-to-cell signal-regulated virulence factor. Plant Physiol 2009, 149:1017-1027.

101. Jenal U, Malone J: Mechanisms of cyclic-di-GMP signaling in bacteria. Annu Rev Genet 2006, 40:385-407.

102. Ryan RP, Fouhy Y, Lucey JF, Crossman LC, Spiro S, He Y-W, Zhang L-H, Heeb S, Cámara M, Williams P, et al: Cell-cell signaling in Xanthomonas campestris involves an HD-GYP domain protein that functions in cyclic di-GMP turnover. Proc Natl Acad Sci U S A 2006, 103:6712-6717. 
103. Tang JL, Liu YN, Barber CE, Dow JM, Wootton JC, Daniels MJ: Genetic and molecular analysis of a cluster of $r p f$ genes involved in positive regulation of synthesis of extracellular enzymes and polysaccharide in Xanthomonas campestris pathovar campestris. Mol Gen Genet 1991, 226:409-417.

104. Chatterjee S, Newman KL, Lindow SE: Cell-to-cell signaling in Xylella fastidiosa suppresses movement and xylem vessel colonization in grape. Mol Plante-Microbe Interact 2008, 21:1309-1315.

105. Jeong KS, Lee SE, Han JW, Yang SU, Lee BM, Noh TH, Cha JS: Virulence reduction and differing regulation of virulence genes in rpf mutants of Xanthomonas oryzae pv. oryzae. Plant Pathol J 2008, 24:143-151.

106. Poplawsky AR, Chun W: pigB determines a diffusible factor needed for extracellular polysaccharide slime and xanthomonadin production in Xanthomonas campestris pv. campestris. J Bacteriol 1997, 179:439-444.

107. He Y-W, Wu J, Zhou L, Yang F, He Y-Q, Jiang B-L, Bai L, Xu Y, Deng Z, Tang $\mathrm{J}-\mathrm{L}$, et al: Xanthomonas campestris diffusible factor is 3-hydroxybenzoic acid and is associated with xanthomonadin biosynthesis, cell viability, antioxidant activity, and systemic invasion. Mol Plant Microbe Interact 2011, 24:948-957.

108. Poplawsky AR, Walters DM, Rouviere PE, Chun W: A gene for a dioxygenase-like protein determines the production of the DF signal in Xanthomonas campestris pv. campestris. Mol Plant Pathol 2005, 6:653-657.

109. Goel AK, Rajagopal L, Nagesh N, Sonti RV: Genetic locus encoding functions involved in biosynthesis and outer membrane localization of xanthomonadin in xanthomonas oryzae pv. Oryzae. J Bacteriol 2002, 184:3539-3548.

110. Zhou L, Wang J-Y, Wang J, Poplawsky A, Lin S, Zhu B, Chang C, Zhou T, Zhang $L-H$, He Y-W: The diffusible factor synthase XanB2 is a bifunctional chorismatase that links the shikimate pathway to ubiquinone and xanthomonadins biosynthetic pathways. Mol Microbio/ 2013, 87:80-93.

111. Büttner D: Protein export according to schedule: architecture, assembly, and regulation of type III secretion systems from plant- and animalpathogenic bacteria. Microbiol Mol Biol Rev 2012, 76:262-310.

112. Delepelaire P: Type I secretion in gram-negative bacteria. Biochim Biophys Acta 2004, 1694:149-161.

113. Masi M, Wandersman C: Multiple signals direct the assembly and function of a type 1 secretion system. J Bacteriol 2010, 192:3861-3869.

114. Stavrinides J: Origin and evolution of phytopathogenic bacteria. In Plant Pathogenic Bacteria: Genomics and Molecular Biology. Edited by Jakson RW. Norfolk, UK: Caister Ac; 2009:330.

115. Moreira MAS, de Souza EC, de Moraes CA: Multidrug efflux systems in gram-negative bacteria. Brazilian J Microbiol 2004, 35:19-28.

116. Burse A, Weingart $H$, Ullrich MS: The phytoalexin-inducible multidrug efflux pump AcrAB contributes to virulence in the fire blight pathogen, Erwinia amylovora. Mol Plant Microbe Interact 2004, 17:43-54.

117. Brown DG, Swanson JK, Allen C: Two host-induced Ralstonia solanacearum genes, acrA and $\operatorname{dinF}$, encode multidrug efflux pumps and contribute to bacterial wilt virulence. Appl Environ Microbiol 2007, 73:2777-2786.

118. Palumbo JD, Kado Cl, Phillips DA: An isoflavonoid-inducible efflux pump in agrobacterium tumefaciens is involved in competitive colonization of roots. J Bacteriol 1998, 180:3107-3113.

119. Poole K: Bacterial Multidrug Efflux Pumps Serve Other Functions. Microbe 2008, 3:179-185

120. Kuroda T, Tsuchiya T: Multidrug efflux transporters in the MATE family. Biochim Biophys Acta 2009, 1794:763-768.

121. Papanikou E, Karamanou S, Economou A: Bacterial protein secretion through the translocase nanomachine. Nat Rev Microbio/ 2007, 5:839-851.

122. Alvarez-Martinez CE, Christie PJ: Biological diversity of prokaryotic type IV secretion systems. Microbiol Mol Biol Rev 2009, 73:775-808.

123. Fronzes R, Christie PJ, Waksman G: The structural biology of type IV secretion systems. Nat Rev Micro 2009, 7:703-714

124. Guglielmini J, de la Cruz F, Rocha EPC: Evolution of conjugation and type IV secretion systems. Mol Biol Evol 2012, 30:315-331.

125. Alegria MC, Souza DP, Andrade MO, Docena C, Khater L, Ramos CHI, Ana C, Silva R, Farah CS, Silva ACR: Identification of New protein-protein interactions involving the products of the chromosome- and plasmid-encoded type IV secretion loci of the phytopathogen xanthomonas axonopodis pv. Citri. J Bacteriol 2005, 187:2315-2325.

126. Souza DP, Andrade MO, Alvarez-martinez CE, Arantes GM, Chuck S, Salinas RK: A component of the xanthomonadaceae type IV secretion system combines a VirB7 motif with a N0 domain found in outer membrane transport proteins. PLoS Pathog 2011, 7:e1002031.
127. Juhas M, Crook DW, Dimopoulou ID, Lunter G, Harding RM, Ferguson DJP, Hood DW: Novel type IV secretion system involved in propagation of genomic islands. J Bacterio/ 2007:761-771

128. Silverman JM, Brunet YR, Cascales E, Mougous JD: Structure and regulation of the type VI secretion system. Annu Rev Microbiol 2012, 66:453-472

129. Szczesny R, Jordan M, Schramm C, Schulz S, Cogez V, Bonas U, Büttner D: Functional characterization of the Xcs and Xps type II secretion systems from the plant pathogenic bacterium Xanthomonas campestris pv vesicatoria. New Phytol 2010, 187:983-1002.

130. Boraston AB, Bolam DN, Gilbert HJ, Davies GJ: Carbohydrate-binding modules: fine-tuning polysaccharide recognition. Biochem J 2004, 382:769-781.

131. Stavrinides J, Ma W, Guttman DS: Terminal reassortment drives the quantum evolution of type III effectors in bacterial pathogens. PLOS Pathog 2006, 2:e104.

132. Fenselau S, Bonas U: Sequence and expression analysis of the $h r p B$ pathogenicity operon of Xanthomonas campestris pv. campestris which encodes eight proteins with similarity to components of the Hrp, Ysc, Spa, and Fli secretion systems. Mol Plant Microbe Interact 1995, 8:845-854

133. Cunac S, Boucher C, Genin S: Characterization of the cis-acting regulatory element controlling HrpB-mediated activation of the type III secretion system and effector genes in Ralstonia solanacearum. J Bacteriol 2004 186:2309-2318.

134. Koebnik R, Krüger A, Thieme F, Urban A, Bonas U: Specific binding of the xanthomonas campestris pv. Vesicatoria AraC-type transcriptional activator HrpX to plant-inducible promoter boxes. J Bacteriol 2006, 188:7652-7660.

135. Schmidtke C, Findeiss S, Sharma CM, Kuhfuss J, Hoffmann S, Vogel J, Stadler PF, Bonas U: Genome-wide transcriptome analysis of the plant pathogen Xanthomonas identifies sRNAs with putative virulence functions. NuCl Acids Res 2012, 40:2020-2031.

136. Palmer GC, Jorth PA, Whiteley M: The role of two Pseudomonas aeruginosa anthranilate synthases in tryptophan and quorum signal production. Microbiology 2013, 159:959-969.

137. Alavi SM, Poussier S, Manceau C: Characterization of ISXax1, a novel insertion sequence restricted to Xanthomonas axonopodis pv. phaseoli (variants fuscans and non-fuscans) and Xanthomonas axonopodis pv. vesicatoria. Appl Environ Microbiol 2007, 73:1678-1682.

138. Monteiro-Vitorello CB, de Oliveira MC, Zerillo MM, Varani AM, Civerolo E, van Sluys M-A: Xylella and Xanthomonas Mobil'omics. OMICS 2005, 9:146-159.

139. Mahillon J, Chandler M: Insertion sequences. Microbiol Mol Biol Rev 1998, 62:725-774.

140. Shieh G-J, Lin C-H, Kuo J-L, Kuo T-T: Characterization of an open reading frame involved in site-specific integration of filamentous phage Cf1t from xanthomonas campestris pv. Citri. Gene 1995, 158:73-76.

141. Qian W, Jia Y, Ren SX, He YQ, Feng JX, Lu LF, Sun Q, Ying G, Tang DJ, Tang $H$, et al: Comparative and functional genomic analyses of the pathogenicity of phytopathogen Xanthomonas campestris pv. campestris. Genome Res 2005, 15:757-767.

142. El-Yacoubi B, Brunings AM, Yuan Q, Shankar S, Gabriel DW: In planta horizontal transfer of a major pathogenicity effector gene. Appl Environ Microbiol 2007, 73:1612-1621.

143. Brunnings AM, Gabriel DW: Xanthomonas citri: breaking the surface. Mol Plant Pathol 2003, 4:141-157.

144. Liu R, Ochman H: Stepwise formation of the bacterial flagellar system. Proc Natl Acad Sci U S A 2007, 104:7116-7121.

145. Swings J, Vauterin L, Kersters K: The bacterium Xanthomonas. In Xanthomonas. Edited by Swings J, Civerolo E. London, United Kingdom: Chapman \& Hall; 1993:121-156.

146. Ronald PC, Beutler B: Plant and animal sensors of conserved microbial signatures. Science 2010, 330:1061-1064.

147. Macnab RM: How bacteria assemble flagella. Annu Rev Microbiol 2003, 57:77-100.

148. Yao J, Allen C: Chemotaxis is required for virulence and competitive fitness of the bacterial wilt pathogen ralstonia solanacearum. J Bacteriol 2006, 188:3697-3708.

149. Dzinic SH, Luercio M, Ram JL: Bacterial chemotaxis differences in Escherichia coli isolated from different hosts. Can J Plant Pathol 2008, 54:1043-1052

150. Noël L, Thieme F, Nennstiel D, Bonas U: Two novel type III-secreted proteins of Xanthomonas campestris pv. vesicatoria are encoded within the hrp pathogenicity island. J Bacteriol 2002, 184:1340-1348. 
151. Hocquet $D$, Llanes $C$, Thouverez $M$, Kulasekara HD, Bertrand X, Plésiat $P$, Mazel D, Miller SI: Evidence for induction of integron-based antibiotic resistance by the SOS response in a clinical setting. PLoS Pathog 2012, 8:e1002778.

152. Gillings MR, Holley MP, Stokes HW, Holmes AJ: Integrons in Xanthomonas: a source of species genome diversity. Proc Natl Acad Sci U S A 2005, 102:4419-4424.

153. Kuo $\mathrm{C}-\mathrm{H}$, Ochman $\mathrm{H}$ : The extinction dynamics of bacterial pseudogenes. PloS Genet 2010, 6:e1001050.

154. Tutar Y: Pseudogenes. Comp Funct Genomics 2012, 2012:6-9.

155. Carreira A, Ferreira LM, Loureiro V: Brown pigments produced by yarrowia lipolytica result from extracellular accumulation of homogentisic acid. Appl Environ Microbiol 2001, 67:3463-3468.

156. Nemergut DR, Robeson MS, Kysela RF, Martin AP, Schmidt SK, Knight R: Insights and inferences about integron evolution from genomic data. BMC Genomics 2008, 9:261.

157. Aury J-M, Cruaud C, Barbe V, Rogier O, Mangenot S, Samson G, Poulain J, Anthouard V, Scarpelli C, Artiguenave F, et al: High quality draft sequences for prokaryotic genomes using a mix of new sequencing technologies. BMC Genomics 2008, 9:603.

158. Thébaut P, Servant F, Schiex T, Gouzy J: L'environnement iANT: integrated annotation tool. In JOBIM Conference Proceedings: 3-5 may 2000; Montpellier, France. Montpellier: ENSA \& LIRM; 2000:361-365.

159. Schiex T, Gouzy J, Moisan A, de Oliveira Y: FrameD: a flexible program for quality check and gene prediction in prokaryotic genomes and noisy matured eukaryotic sequences. Nucl Acids Res 2003, 31:3738-3741.

160. Gattiker A, Michoud K, Rivoire C, Auchincloss AH, Coudert E, Lima T, Kersey P, Pagni M, Sigrist CJA, Lachaize C, et al: Automated annotation of microbial proteomes in SWISS-PROT. Comput Biol Chem 2003, 27:49-58

161. Serres MH, Riley M: MultiFun, a multifunctional classification scheme for Escherichia coli K-12 gene products. Microb Comp Genomics 2000, 5:205-222.

162. Li L, Stoeckert CJJ, Roos DS: OrthoMCL : identification of ortholog groups for eukaryotic genomes. Genome Res 2003, 13:2178-2189.

163. Darling AE, Mau B, Perna NT: progressiveMauve: multiple genome alignment with gene gain, loss and rearrangement. PLoS One 2010, 5:e11147.

164. Hall TA: BioEdit: a user-friendly biological sequence alignement editor and analysis program for Windows 95/98/NT. Nucleic Acids Symp Ser 1999, 41:95-98.

165. Guindon S, Dufayard J-F, Lefort V, Anisimova M, Hordijk W, Gascuel O: New algorithms and methods to estimate maximum-likelihood phylogenies: assessing the performance of PhyML 3.0. Sys Biol 2010, 59:307-321.

166. Tamura K, Peterson D, Peterson N, Stecher G, Nei M, Kumar S: MEGA5: molecular evolutionary genetics analysis using maximum likelihood, evolutionary distance, and maximum parsimony methods. Mol Biol Evol 2011, 28:2731-2739.

doi:10.1186/1471-2164-14-761

Cite this article as: Darrasse et al:: Genome sequence of Xanthomonas fuscans subsp. fuscans strain 4834-R reveals that flagellar motility is not a general feature of xanthomonads. BMC Genomics 2013 14:761.

\section{Submit your next manuscript to BioMed Central and take full advantage of:}

- Convenient online submission

- Thorough peer review

- No space constraints or color figure charges

- Immediate publication on acceptance

- Inclusion in PubMed, CAS, Scopus and Google Scholar

- Research which is freely available for redistribution 